\title{
LA NATURALEZA DEL ESTADO DE ALARMA Y SU PRESUPUESTO HABILITANTE ${ }^{1}$
}

\author{
Antonio Arroyo Gil \\ Profesor Ayudante Doctor (acr. Titular) de Derecho Constitucional, \\ Universidad Autónoma de Madrid
}

Cómo citar este artículo / Citation: Arroyo Gil, A. (2021). La naturaleza del estado de alarma y su presupuesto habilitante. Garrido López, C. (coord.) Excepcionalidad y Derecho: el estado de alarma en España, Colección Obras colectivas, Fundación Manuel Giménez Abad, Zaragoza.

DOI: https://doi.org/10.47919/FMGA.OC21.0001

SUMARIO: I. ALGUNAS CONSIDERACIONES PRELIMINARES DE CARÁCTER GENERAL SOBRE LOS ESTADOS EXCEPCIONALES Y SU REGULACIÓN CONSTITUCIONAL. II. LA LEY ORGÁNICA REGULADORA DE LOS ESTADOS EXCEPCIONALES, CON ESPECIAL ATENCIÓN AL ESTADO DE ALARMA. 1. Precedentes. 2. Las disposiciones comunes a los tres estados excepcionales. III. NATURALEZA DEL ESTADO DE ALARMA. IV. SUPUESTOS DE DECLARACIÓN DEL ESTADO DE ALARMA. V. BREVE REFERENCIA A LAS CUATRO EXPERIENCIAS PRÁCTICAS DE DECLARACIÓNDEL ESTADO DE ALARMA. VI. CONCLUSIONES

\section{ALGUNAS CONSIDERACIONES PRELIMINARES DE CARÁCTER} GENERAL SOBRE LOS ESTADOS EXCEPCIONALES Y SU REGULACIÓN CONSTITUCIONAL

Lo primero que hace el art. $116 \mathrm{CE}$, precepto constitucional de los estados excepcionales (alarma, excepción y sitio), cuya ubicación en el Título V ("De las

\footnotetext{
${ }^{1}$ El presente trabajo se enmarca dentro del Proyecto coordinado: "Diseño constitucional y calidad democrática (DICOCADE)" [Subproyecto 1: "El Control y responsabilidad política en el estado constitucional con especial referencia al Parlamento en el contexto multinivel (CORE)"] (PID2019-104414GB-C31 DER - IP: José Tudela Aranda).
} 
relaciones entre el Gobierno y las Cortes Generales"), por cierto, no parece la más adecuada ${ }^{2}$, es remitirse a una ley orgánica, que será la que los regule con carácter, en buena medida, configurador (apartado 1). $Y$ es que de la Constitución, en efecto, no es posible deducir en qué consiste cada uno de estos estados ni en qué supuestos podrán ser declarados, dado que la misma se limita a prever su procedimiento de declaración (apartados 2, 3 y 4), así como a establecer ciertas cautelas relativas a la imposibilidad de disolución del Congreso mientras esté declarado alguno de estos estados; la convocatoria automática de las Cámaras si no estuvieran en período de sesiones; la prohibición de interrupción de su funcionamiento, así como de los demás poderes constitucionales del Estado, durante la vigencia de tales estados; y la asunción por la Diputación permanente del Congreso de las competencias de este en el caso de que el mismo se encontrase disuelto o hubiera expirado su mandato y se produjere alguna de las situaciones que dan lugar a cualquiera de estos estados (apartado 5), pero que el propio precepto no menciona. Concluye este artículo 116 CE con una prohibición taxativa de modificar el principio de responsabilidad del Gobierno y de sus agentes reconocidos en la Constitución y en las leyes cuando se declare alguno de esos estados excepcionales (apartado 6).

Además de este artículo, se ha de tener presente lo previsto en otros preceptos constitucionales que, de manera más o menos directa o tangencial, hacen también referencia a los estados excepcionales. Así, el art. 169 CE prohíbe iniciar la reforma constitucional en tiempos de guerra o de vigencia de alguno de ellos. $\mathrm{Y}$ el art. 117.5 CE, al tiempo que reconoce, en primer lugar y con carácter general, el principio de unidad jurisdiccional como base de la organización y funcionamiento de los Tribunales, acto seguido se remite a una ley para regular el ejercicio de la jurisdicción militar en el ámbito estrictamente castrense y en los supuestos de estado de sitio, de acuerdo con los principios de la Constitución, de donde cabría derivar que más allá de ese ámbito (el castrense) y de ese supuesto (estado de sitio) la jurisdicción militar no tiene

\footnotetext{
2 FERNÁNDEZ SEGADO, F., "La Ley Orgánica de los estados de alarma, excepción y sitio", Revista de Derecho Político, 11, 1981, p. 87. Para CARRO MARTínEZ, A., "Artículo 116. Situaciones de anormalidad constitucional", en ALZAGA VILLAAMIL, Ó., (dir.), Comentarios a la Constitución Española de 1978, Tomo IX (arts. 113 a 127), Cortes Generales-Edersa, Madrid, 1998, p. 247, "sólo se comprende la ubicación de este precepto desde un punto de vista negativo o residual; se colgó al final del Título V, porque no se encontró otro sitio mejor".
} 
cabida, sin que una norma infraconstitucional pueda, por tanto, prever su extensión a otros ámbitos o supuestos ${ }^{3}$.

Mención aparte merece lo dispuesto en el apartado 1 del art. $55 \mathrm{CE}$, que es el que autoriza la suspensión de determinados derechos cuando se declare el estado de excepción o de sitio. En concreto, podrán suspenderse los derechos y libertades reconocidos en los siguientes preceptos (numerus clausus):

- art. 17 (derecho a la libertad y a la seguridad, incluida la detención preventiva, los derechos del detenido -que solo podrán ser suspendidos en el estado de sitio- y el habeas corpus);

- art. 18 apartados 2 (inviolabilidad del domicilio) y 3 (secreto de las comunicaciones);

- $\quad$ art. 19 (libre elección de residencia y derecho a circular por el territorio nacional, así como el derecho a entrar y salir libremente de España);

- art. 20 apartados 1.a) (libertad de expresión) y d) (libertad de comunicación e información, incluido el derecho a la cláusula de conciencia y al secreto profesional en el ejercicio de esas libertades en los términos que la ley, a la que se remite la propia Constitución, lo regule), y 5 (secuestro de publicaciones, grabaciones y otros medios de información);

- $\quad$ art. 21 (derecho de reunión y manifestación);

- $\quad$ art. 28 apartado 2 (derecho de huelga); y

- $\quad$ art. 37 apartado 2 (derecho de trabajadores y empresarios a adoptar medidas de conflicto colectivo).

La taxatividad de este art. 55.1 CE respecto a la posibilidad de suspender solo determinados derechos (no otros, por tanto) ${ }^{4}$, y únicamente cuando se acuerde la declaración de los estados de excepción o de sitio (no el de alarma, por tanto $)^{5}$, ha de interpretarse siempre a la luz del principio favor libertatis (que

\footnotetext{
${ }^{3}$ Conviene tener presente esta observación cuando hagamos referencia, más adelante, al primer estado de alarma declarado en diciembre de 2010 para hacer frente a la huelga abusiva de los controladores aéreos.

${ }^{4}$ Son los que integrarían la llamada "Constitución suspendible", en la terminología acuñada por Pedro Cruz, para quien "este principio de enumeración ('enumeratio ergo limitatio') puede considerarse como el principio estructural básico en el modelo del 'estado excepcional' adoptado por nuestra Constitución" (CRUZ VILLALÓN, P., Estados excepcionales y suspensión de garantías, Tecnos, Madrid, 1984, pp. 48-49).

${ }^{5}$ El Tribunal Constitucional se encargó de dejarlo perfectamente claro: "[a] diferencia de los estados de excepción y sitio, la declaración del estado de alarma no permite la suspensión de ningún derecho fundamental (art. 55.1 CE contrario sensu), aunque sí la adopción de medidas que pueden suponer limitaciones o restricciones a su ejercicio" (STC 83/2016, de 28 de abril FJ 8).
} 
constituye una pauta hermenéutica bien asentada en la jurisprudencia constitucional) $)^{6}$. Quiere esto decir que la suspensión de los referidos derechos solo podrá producirse cuando sea estrictamente necesario, con el alcance que sea preciso y durante el tiempo imprescindible, lo que en todo caso habrá de justificarse debidamente. Argumentos estos que también serían aplicables en relación con la restricción o limitación (nunca suspensión) de los derechos fundamentales que, como el Tribunal Constitucional ha reconocido, se pueda llevar a cabo durante la declaración del estado de alarma (STC 83/2016, de 28 de abril - FJ 8).

Este sucinto tratamiento constitucional de los estados excepcionales se ve complementado con las previsiones de la ley orgánica que, por remisión de la propia Constitución, se encarga de la regulación de los mismos: la Ley Orgánica 4/1981, de 1 de junio, de los estados de alarma, excepción y sitio (LOAES). Es, en efecto, esta norma la que, con carácter plenamente configurador, define en qué supuestos se puede declarar cada uno de estos estados $^{7}$, dado que, como hemos señalado ya, la Constitución no ofrece al respecto ninguna pista ${ }^{8}$ (salvo, quizás, en relación con el estado de sitio, en la medida en que el art. 117.5 CE lo vincula al ejercicio de la jurisdicción militar). Sin embargo, pese a ese silencio, cabría entender que el constituyente, puesto que menciona de manera expresa dichos estados, parte de una determinada "precomprensión" del contenido de cada uno de ellos; un contenido que el legislador se encargará de explicitar, si bien con un margen de libertad extraordinariamente amplio, ya que solo estará sujeto a las limitadas prescripciones constitucionales referidas.

\footnotetext{
${ }^{6}$ Valgan, por todas, las SSTC 66/1995, de 8 de mayo (FJ 3); y 137/2016, de 18 de julio (FJ 2).

${ }^{7}$ Esto es lo que, empleando una terminología usual en el ámbito de unas normas igualmente excepcionales, pese al uso abusivo que se viene haciendo de ellas, los decretos leyes, podríamos llamar el "presupuesto de hecho habilitante".

${ }^{8}$ Lo que ha sido criticado, desde un primer momento, por la doctrina científica, que aunque reconoce que la Constitución no podía haber previsto de manera exhaustiva los supuestos concretos en que sería posible declarar cada uno de estos estados, sí hubiera sido deseable que, al menos, se hubiese hecho eco de los mismos, "incluso con una fórmula tan genérica como la del art. 10.1 de esta ley" (FERNÁNDEZ SEGADO, F., "La Ley Orgánica..., p. 88).

Desde otra perspectiva, Juan José Solozábal considera que el hecho de que la norma no pueda prever todas las actuaciones del Ejecutivo, así como la necesaria indeterminación de la regulación, son rasgos característicos del derecho de excepción, destinados a evitar que el Gobierno se encuentre atado de manos por el principio de legalidad entendido de modo rígido. Antes bien, según Solozábal, el Gobierno se halla sujeto, más que a una base propiamente dicha, a un marco, con un sentido habilitador más que referencial. Vid. SOLOZÁBAL ECHAVARRÍA, J. J., "Algunas consideraciones constitucionales sobre el estado de alarma", en BIGLINO CAMPOS, P., DURÁN ALBA, J. F. (dirs.), Los efectos horizontales de la COVID sobre el sistema constitucional, Col. Obras colectivas, Fundación Manuel Giménez Abad, Zaragoza, 2020, p. 4.
} 
Como cabe imaginar, esta indefinición constitucional resulta muy problemática a causa de su gran apertura, pues a partir de la literalidad del texto constitucional cabría entender que, si dejamos de lado ahora el estado de sitio, dada su singular naturaleza vinculada a lo militar que apunta indefectiblemente hacia graves crisis del orden constitucional (de la soberanía o de la integridad territorial $)^{9}$, tanto el estado de alarma como el de excepción podrían tener un alcance similar, en relación con los supuestos en que podrían ser declarados, que solo cabría diferenciar en función de que fuera necesario, o no, proceder a la suspensión de ciertos derechos fundamentales. Dicho de otro modo: a partir de la Constitución no encontramos obstáculo alguno para entender que la declaración del estado de alarma o de excepción solo depende de que sea preciso, o no, proceder a la suspensión de alguno de los derechos reconocidos en el art. 55.1 $\mathrm{CE}^{10}$.

Sin embargo, esta, que se ha calificado como "concepción gradualista" (por el mayor grado de gravedad de la emergencia a que se tendría que responder en un estado y en otro ${ }^{11}$, lo que resultaría coherente con un mayor o menor protagonismo del Congreso de los Diputados en su declaración ${ }^{12}$ ), no ha sido la interpretación adoptada por el legislador orgánico. Por el contrario, este ha entendido que la declaración de cada uno de esos estados representa una respuesta a unos hechos o supuestos diferentes, todos ellos de carácter excepcional, que no se pueden abordar debidamente de conformidad con la legislación ordinaria ("concepción pluralista") ${ }^{13}$. Aunque después lo veremos

\footnotetext{
${ }^{9}$ Vid. FERNÁNDEZ SEGADO, F., "La Ley Orgánica..., p. 111.

${ }^{10}$ A esta idea apunta Carlos Garrido cuando, tras reconocer que la LOAES "se decantó por una 'lectura pluralista' de nuestro derecho constitucional de excepción en la que los tres estados fueran configurados como instrumentos distintos para hacer frente a emergencias sustancialmente distintas", señala a continuación que "[c]onstitucionalmente, sin embargo, nada avalaba una opción tan rígida que prescindiera de un posible uso gradual de dichos estados" (GARRIDO LÓPEZ, C., "La naturaleza bifronte del estado de alarma y el dilema limitación-suspensión de derechos", Teoría y realidad constitucional, 46, 2020, p. 375). Con un enfoque más amplio, Juan José Solozabal cree que "la insistencia en las diferencias entre los estados de excepción impide ver que estos comparten elementos comunes" (SOLOZÁBAL ECHAVARRÍA, J. J., "Algunas consideraciones constitucionales..., p. 2).

${ }_{11}$ Así parece entenderlo, entre otros, ABA CATORIA, A., "El estado de alarma en España", TRC, 28, 2011, p. 324, en relación incluso con los tres estados excepcionales, cuando sostiene que "[s]on tres estados de crisis constitucional, enumerados de menor a mayor gravedad, pero que, en esencia, responden al mismo objetivo, responder a las situaciones de emergencia que se puedan producir poniendo en jaque al Estado".

${ }^{12}$ BERDUGO GÓMEZ DE LA TORRE, I., "Garantías en la Constitución ante la suspensión de derechos fundamentales", Sistema: revista de ciencias sociales, 42, 1981, p. 63.

${ }^{13}$ CRUZ VILLALÓN, P., Estados excepcionales..., p. 51. Esta concepción es ampliamente compartida entre la doctrina científica. Véase, entre otros, TORRES MURO, I., "Artículo 116", en RODRÍGUEZ-PIÑERO Y BRAVO FERRER, M., CASAS BAAMONDE, Ma. E. (dirs.), Comentarios a la Constitución Española, BOE - Wolters Kluwer, Madrid, 2018, Tomo II, p. 632.
} 
con más detalle, interesa adelantar aquí, por lo que se refiere a los estados de alarma y excepción, que tal diferenciación no siempre resulta del todo clara, en la medida en que hay algunos puntos de conexión entre los presupuestos de hecho habilitantes de uno y otro que pueden generar cierta confusión.

Por otro lado, y aunque no constituya el objeto principal de este trabajo, merece la pena que en estas observaciones preliminares hagamos también una somera referencia a otra cuestión que tiene asimismo un gran interés: los estados excepcionales del art. $116 \mathrm{CE}$-es una obviedad- son derecho constitucional $^{14}$, pese a que su activación pueda suponer una seria limitación o restricción (estado de alarma) o, incluso, una suspensión (estados de excepción y sitio) de ciertas partes de la Constitución. Esto no plantearía demasiados problemas (jurídicos, al menos) si tal afectación se limitase a la prevista en la propia Constitución, a saber, los derechos referidos en el art. 55.1 CE, la corrección al principio de unidad jurisdiccional prevista en el art. 117.5 CE, o la limitación a la facultad de iniciativa de reforma constitucional establecida en el art. 169 CE. El problema es que la LOAES prevé también que la declaración de esos estados puede suponer una afectación severa a otras reglas o principios constitucionales, particularmente los relativos a la distribución de competencias entre el Estado central y las Comunidades autónomas. No nos podemos detener ahora en esta cuestión, pero sí conviene ser conscientes de que tal cosa sucede a partir de una remisión constitucional, insisto, sumamente abierta, como es la contenida en el apartado 1 del art. 116 $\mathrm{CE}^{15}$.

${ }^{14} \mathrm{O}$, como señala Carlos Garrido, "el estado excepcional no es un derecho al margen del derecho" (GARRIDO LÓPEZ, C., "La naturaleza bifronte..., p. 373). En el mismo sentido, VELASCO CABALLERO, F., "Estado de alarma y distribución territorial del poder", El Cronista del Estado Social y Democrático de Derecho, 86-87, 2020, p. 78, sostiene que "las situaciones de emergencia se legitiman y delimitan en la propia Constitución. Por tanto, no son situaciones alternativas al orden constitucional, sino sólo modulaciones -algunas muy importantes- del orden constitucional ordinario".

${ }^{15}$ A tal efecto, SOLOZÁBAL ECHAVARRÍA, J. J., "Algunas consideraciones constitucionales..., pp. 8 y 14, sostiene que "[n]o es preciso anudar la intervención del Gobierno a un título competencial específico (...) sino a su función constitucional de dirigir la política de Estado"; más en concreto, en relación con el estado de alarma declarado por Real Decreto 463/2020 para hacer frente a la crisis sanitaria provocada por la pandemia de la Covid-19, que después veremos, sostiene que la decisión gubernamental integra, junto con la Constitución y la LOAES, "el sistema de fuentes del derecho de excepción (...) con los efectos desplazatorios durante el estado de alarma de la legalidad ordinaria (...) afectan[do] también al derecho autonómico, [sin que tenga] sentido resolver el conflicto entre el derecho autonómico y el general que pueda producirse afirmando el carácter prevalente o, en su caso, supletorio del derecho general. La preeminencia en la aplicación del derecho de excepción es la que corresponde al derecho de crisis, quedando fuera de consideración reglas de resolución propias de los conflictos competenciales en tiempos ordinarios", tal y como había defendido 
El problema de fondo, en todo caso, es que a través de esta normativa de excepción se pretende llevar a efecto una operación sumamente compleja y delicada: regular la excepción, aún a sabiendas de que esta se puede presentar de muy diferentes modos, no siempre previsibles. $Y$ hacerlo de tal forma que se garantice, tanto como sea posible, el respeto a la organización y funcionamiento de los poderes constitucionales del Estado, especialmente los representativos, pese a saber que serán los de carácter ejecutivo los que se verán fundamentalmente reforzados ${ }^{16}$, en la medida en que son ellos los que, por su propia naturaleza, se encuentran en mejores condiciones de hacer frente a la situación de excepcionalidad, a la que se ha de ofrecer una respuesta que no es posible dar mediante el ejercicio del derecho ordinario. Es precisamente a esto a lo que se refiere el apartado 5 del art. $116 \mathrm{CE}$ a que antes hacíamos referencia. El constituyente, en efecto, puso especial cuidado en dejar constancia expresa de que, sin perjuicio del relevante papel que corresponde al Gobierno en la declaración (o propuesta de declaración) de los estados de alarma, excepción y sitio, y, sobre todo, en la ejecución de las medidas concretas que se adopten a su amparo, se ha de primar, sin embargo, la permanencia e intervención parlamentaria, en particular, la del Congreso de los Diputados, sede principal de la representación popular, y corazón, por tanto, del sistema democrático. De ahí que tan solo en el estado de alarma la intervención del Gobierno, declarándolo durante un plazo máximo de quince días, pueda producirse autónomamente, con el único requisito de informar al Congreso de los Diputados. En todos los demás supuestos (prórroga del estado de alarma y declaración de los estados de excepción y sitio) la

Francisco Velasco. Vid. VELASCO, F., "Estado de alarma y distribución territorial del poder", núm. 86-87, 2020, de El Cronista del Estado Social y Democrático de Derecho (pp. 78-87).

Pues bien, sin poner en duda lo acertado de esta afirmación del prof. Solozábal, me sigue pareciendo que la apertura e indeterminación de la remisión constitucional a la ley puede plantear alguna duda en relación con el alcance posible de la declaración del estado de alarma sobre la distribución constitucional de competencias, más aún teniendo en cuenta la difusa previsión del propio art. $116 \mathrm{CE}$, que en su apartado 5 dispone que el funcionamiento de las Cámaras "así como el de los demás poderes constitucionales del Estado, no podrán interrumpirse durante la vigencia de estos estados".

A este respecto, SIEIRA MUCIENTES, S., "Estado de alarma", Eunomía, 19, 2020, p. 278, sostiene que "[e]l estado de alarma no produce ningún tipo de suspensión ni derogación del sistema autonómico", si bien admite que "si la autoridad competente es el Gobierno, pueda tomar medidas que incidan directamente en los ámbitos de competencia de las Comunidades Autónomas".

${ }^{16}$ Tal y como apunta Solozábal, "[e]l derecho de la crisis refuerza significativamente 'la posición constitucional del Gobierno' pues su propósito sin duda es apoderarle, como órgano capaz de adoptar las decisiones que las circunstancias requieran, de manera inmediata y del modo más contundente posible". Vid. SOLOZÁBAL ECHAVARRÍA, J. J., "Algunas consideraciones constitucionales..., p. 4. 
intervención del Congreso resulta decisiva e insustituible. $Y$ de ahí también que no se pueda proceder a la disolución de este mientras estén declarados estos estados y de que queden automáticamente convocadas las Cámaras si no estuvieran en período de sesiones. A la misma idea responde la previsión del párrafo final del susodicho apartado 5 del art. $116 \mathrm{CE}$ en relación con la Diputación Permanente de aquel, más allá de que la misma sea perfectamente superflua, en la medida en que lo que prevé ya está previsto en el art. 78.3 $\mathrm{CE}^{17}$.

Más allá de su literalidad, de estas previsiones constitucionales se deriva una idea incuestionable: la voluntad decidida del constituyente de que el protagonismo del Gobierno, en tanto que órgano ejecutivo, durante la vigencia de estos estados excepcionales, no solo no se puede traducir en una subordinación, desplazamiento o, menos aún, interrupción (del funcionamiento) de las Cortes Generales, y, especialmente, del Congreso de los Diputados, sino que además aquel, el Gobierno (y sus agentes), ha de continuar sometido al principio de responsabilidad reconocido en la Constitución y en las leyes, tal y como dispone el apartado 6 del art. 116 CE. En definitiva, el deseo del constituyente es que la declaración de estos estados excepcionales no altere el núcleo duro del principio del Estado democrático de Derecho, que, entre otras cosas, en nuestro sistema exige que el Gobierno haya de contar en todo momento con la confianza del Parlamento, quedando siempre sujeto a su control, y que incluso el derecho de excepción haya de moverse dentro de unos cauces constitucionales que no puede desbordar. $Y$ es que a diferencia de lo que sucede en otros ordenamientos jurídicos, en el nuestro la reacción frente a las situaciones de máxima gravedad no trae consigo la posibilidad de activar una especie de "cláusula de plenos poderes" a favor del Gobierno (o algo similar al bill of indemnity de la tradición inglesa), con el fin de que el mismo goce de la máxima libertad para hacer frente al grave desafío que se haya presentado. Dicha cláusula, con toda razón, no está prevista, pues la misma, en el fondo, supone la negación del propio Estado de Derecho. Otra cosa es que la fuerza de los hechos sea de tal magnitud que pueda llegar a provocar un desbordamiento irrefrenable de la legalidad vigente. De suceder algo así nos encontraríamos ya en otro escenario, cuyo desenlace final será prácticamente imposible de prever de antemano. Si acaso, a lo más a lo que se podría apelar en una situación como esa es a la necesidad de recuperar cuanto antes el

${ }^{17}$ CARRO MARTíNEZ, A., "Artículo 116..., p. 249. 
respeto a la legalidad desbordada, en el supuesto de que ello sea aún posible. $Y$ exigir a todos los poderes y autoridades públicos que orienten su acción a ese fin, por lo que habrán de responder, llegado el momento.

En directa relación con esto, hay que entender que el derecho de excepción, por más que sea derecho previsto en la propia Constitución (y en las leyes que la desarrollan), puede llegar a rozar los confines de esta. De ahí que no sean descartables, como la experiencia demuestra, decisiones o actuaciones cuya constitucionalidad puede ser muy controvertida, pero que, sin embargo, pueden resultar muy efectivas para conjurar el peligro que motiva su adopción (como el primer ejemplo de declaración del estado de alarma en diciembre de 2010, a que luego nos referiremos, puso de manifiesto). Sea como fuere, ese (el del desbordamiento constitucional) es un riesgo que se ha de tratar de conjurar siempre. Como principio general, la defensa de la Constitución, lo que a estos efectos viene a ser tanto como la defensa del Estado de Derecho, ha de llevarse a cabo dentro de los márgenes que la propia Constitución prevé, más aún cuando estos son lo suficientemente amplios como para poder adoptar medidas muy severas sin necesidad de acudir a otras que supongan ya un quebrantamiento de dicho marco constitucional.

Es en este sentido en el que se han de entender las siguientes palabras del profesor Cruz Villalón: "el derecho de excepción tiene que cumplir el objetivo de protegerse frente a sí mismo, es decir, tiene que garantizar no solo la superación de la crisis, sino la vuelta a la Constitución legítima”. No obstante, no se puede perder de vista que, como se ha señalado ya, el derecho de excepción es derecho constitucional, y, por eso mismo, no se puede calificar, en sentido estricto, de ilegítimo ${ }^{18}$. Otra cosa es que, como señala este mismo autor, se haya de "evitar que las medidas de suspensión de la Constitución en las que el derecho de excepción consiste no se vuelvan contra la Constitución misma en forma de una amenaza todavía mayor que la que se trata de conjurar", lo que sitúa al constituyente ante la tesitura de "decidir hasta qué punto una Constitución puede ser suspendida, aunque solo sea

\footnotetext{
${ }^{18}$ Por idénticas razones, no se puede compartir la afirmación de Antonio Carro de que "el 116 prevé la suspensión de la vigencia de todo o parte de la Constitución, lo que supone en el fondo un verdadero atentado a la Constitución y a la democracia que la misma prevé" (CARRO MARTíNEZ, A., "Artículo 116..., p. 216). Más allá de ser imprecisa, pues el art. 116 CE no prevé suspensión alguna (pese a lo que este mismo autor señala, con insistencia, más adelante -p. 222-), sino que, por el contrario, la única suspensión es la prevista, con carácter muy limitado, en el art. 55.1 CE, resulta además profundamente inexacta, pues una previsión constitucional no puede ser nunca entendida como un atentado contra la Constitución o la democracia.
} 
temporalmente, sin que ello suponga un daño irreparable en la legitimidad misma de ese orden constitucional"; en definitiva, "[l]a adopción de un derecho de excepción implica (...) un importante cálculo de riesgos por parte del constituyente" ${ }^{19}$.

Ciertamente, el constituyente español podría haber optado o bien por no regular el derecho de excepción ${ }^{20}$, o bien por concentrar en un órgano constitucional todos los poderes del Estado para hacer frente a la situación de crisis ("dictadura constitucional") ${ }^{21}$. Sin embargo, su decisión de hacerlo merece ser celebrada, pues, además de representar un ejercicio de confianza en que la nueva institucionalidad (Gobierno y, sobre todo, Parlamento, en especial, el Congreso de los Diputados) podrá hacer frente, dentro del marco constitucional, y según disponga la correspondiente ley orgánica de desarrollo, a las graves situaciones que se puedan llegar a presentar en el futuro, constituye también un esfuerzo, merecedor de reconocimiento, por mantener el ejercicio del poder dentro de los márgenes del Derecho, por más que estos se vean sumamente flexibilizados. El derecho de excepción constitucionalizado supone, en definitiva, el intento último del constituyente de defender (también con carácter preventivo) la vigencia de la Constitución incluso en los peores escenarios imaginables (crisis naturales, políticas o sociales) o frente a sus más acérrimos enemigos (interiores y exteriores) ${ }^{22}$.

\footnotetext{
${ }^{19}$ CRUZ VILLALÓN, P., Estados excepcionales..., pp. 24 ss.

${ }^{20}$ Cruz recuerda que, en tales casos, la respuesta a estas "lagunas" voluntarias "suele ser la llamada 'exoneración parlamentaria' de los poderes públicos que se han visto en la necesidad de infringir el ordenamiento; por medio de una 'ley de indemnidad' la representación nacional exime de responsabilidad a unos gobernantes a los que las circunstancias han obligado a quebrantar el ordenamiento. (...) Lo único que, eventualmente, sería necesario demostrar es que se habían reunido las condiciones del 'estado de necesidad'" (CRUZ VILLALÓN, P., Estados excepcionales..., pp. 29-30).

${ }^{21}$ Renunciándose, en tales supuestos, como señala Cruz, "al intento de prever las posibles situaciones de crisis (...) y (...) al intento de delimitar los efectos que las necesidades derivadas de la superación de la emergencia puedan tener sobre el ordenamiento constitucional", y sin que, por tanto, haya "un ámbito de la Constitución que no pueda ser temporalmente sacrificado a la necesidad de superar la crisis" (CRUZ VILLALÓN, P., Estados excepcionales..., p. 33).

${ }_{22} \mathrm{O}$, como dice Juan José Solozábal, "[I]o que el derecho de excepción trata de preservar es un orden mínimo innegable de libertad y seguridad que a pesar de las circunstancias se imponga a los poderes públicos" (SOLOZABBAL ECHAVARRÍA, J. J., "Algunas consideraciones constitucionales..., p. 3).
} 


\section{LA LEY ORGÁNICA REGULADORA DE LOS ESTADOS} EXCEPCIONALES, CON ESPECIAL ATENCIÓN AL ESTADO DE ALARMA

Vista a grandes rasgos la regulación constitucional de los estados excepcionales, y hechas las consideraciones preliminares que nos parecía importante tener en cuenta antes de acometer el estudio de la cuestión principal a la que aquí trataremos de dar respuesta (los supuestos en que cabe declarar el estado de alarma), conviene prestar ahora una singular atención, siquiera sea sucintamente, a los precedentes de la LOAES, así como al Capítulo Primero de la misma, que regula una serie de disposiciones comunes a los tres estados, en la medida en que ello nos permitirá afrontar con mejor fundamento dicho estudio.

\section{Precedentes}

Siguiendo en este punto el excelente resumen de la evolución del derecho de excepción en la historia constitucional española llevado a cabo por el profesor Cruz Villalón en su ya clásico y mencionado trabajo Estados excepcionales y suspensión de garantías, podemos apreciar cómo durante una primera larga etapa de la historia de nuestro constitucionalismo (1812-1869), el tratamiento que aquel había recibido se circunscribía a la llamada "suspensión de garantías" de determinados derechos de libertad. Esta limitada previsión constitucional convivió, a partir de 1835, con un estado excepcional de carácter militar, que, pese a carecer de fundamento constitucional, tuvo importante relevancia práctica (el estado de guerra o sitio). No sería hasta la Ley de Orden Público de 17 de mayo de 1867, al final del periodo isabelino, que se regulan por vez primera tres estados que podríamos calificar de excepcionales: uno llamado "normal" (de carácter esencialmente preventivo), y dos excepcionales en sentido estricto: los de alarma (de carácter civil) y guerra (de carácter militar).

La regulación constitucional del derecho de excepción habrá de esperar, sin embargo, a la Constitución de 1869, que en su art. 31 establece cuáles son los derechos y libertades suspendibles, al tiempo que se remite a la futura aprobación de una Ley de Orden Pública; ley que sería promulgada el 23 de abril del año siguiente y que prevé dos estados excepcionales: de prevención y alarma (de carácter civil) y de guerra (de carácter militar). No obstante, estas previsiones constitucionales y legales quedaron desactivadas a través de la 
interpretación que de las mismas se llevó a cabo por Orden del Regente, de ahí que la Constitución de 1876 suprimiera toda referencia a la Ley de Orden Público, aunque sí autorizase, por primera vez, la suspensión de ciertos derechos fundamentales sin necesidad de habilitación legal alguna si el caso fuera de "grave y notoria urgencia".

Por su parte, la Constitución republicana de 1931, siguiendo la estela de la de 1869, contenía también un precepto de suspensión de garantías (el art. 42) y una referencia expresa a la Ley de Orden Público, que será promulgada el 28 de julio de 1933; ley que contenía una regulación completa del orden público, tanto en situaciones de normalidad como de excepción (al prever, a este último respecto, dos estados de excepcionalidad civil: el de prevención -sin suspensión de garantías- y el de alarma -con posible suspensión de garantías-; y un estado de excepcionalidad militar: el de guerra). Asimismo, en la Constitución de 1931 se otorgaba al Presidente de la República una facultad excepcional a modo de habilitación general: "Ordenar las medidas urgentes que exijan la defensa de la integridad o seguridad de la Nación, dando cuenta inmediata a las Cortes" (art. 76.d).

Finalmente, durante el régimen del general Franco, dejando de lado su carácter no democrático, que desvirtúa toda posible distinción entre derecho ordinario y de excepción, se aprobó una nueva Ley de Orden Público, en 1959, que además de regular el orden público en situaciones de normalidad, preveía también la declaración de dos estados excepcionales: el de excepción (de carácter civil) y el de guerra (de carácter militar) ${ }^{23}$.

A comienzos de 1978, pocos meses antes de aprobarse la Constitución, por tanto, se presentó al Congreso de los Diputados un proyecto de ley de modificación de esta Ley de Orden Público de 1959; aunque no llegó a convertirse en ley, lo cierto es que regulaba el estado de alarma en términos similares a los que después formarían parte del contenido de la futura LOAES $^{24}$.

Finalmente, si fijamos la mirada en el período actual, que se abre con la aprobación de la Constitución de 1978, la primera que, stricto sensu,

\footnotetext{
${ }^{23}$ Vid. CRUZ VILLALÓN, P., Estados excepcionales..., pp. 36-44. Véase, asimismo, CARRO MARTÍNEZ, A., "Artículo 116..., pp. 230-246; y, con más detalle, véase FERNÁNDEZ SEGADO, F., El estado de excepción en el derecho constitucional español, Edersa, Madrid, 1977.

${ }^{24}$ CARRO MARTÍNEZ, A., "Artículo 116..., p. 253.
} 
constitucionaliza los estados excepcionales ${ }^{25}$, podemos constatar que a los pocos meses de entrada en vigor de la misma, en septiembre de 1979, el Consejo de Ministros presentó ante las Cortes Generales un proyecto de ley de seguridad ciudadana, que contemplaba no solo cuestiones relativas a la seguridad pública (art. 149.1.29 $\mathrm{CE}$ ) en situaciones de normalidad, sino que también regulaba las facultades del Ejecutivo para hacer frente a las investigaciones correspondientes a la actuación de bandas armadas 0 elementos terroristas (art. 55.2 CE), las funciones, principios básicos y estatutos de las Fuerzas y Cuerpos de seguridad (art. 104.2 CE) y, esto es lo que más nos interesa ahora, el régimen de los estados excepcionales (art. 116 $\mathrm{CE}$ ), al entender que todo ello respondía a una finalidad común: garantizar la seguridad ciudadana. Sin embargo, este proyecto no prosperó, y el Gobierno decidió finalmente regular en cuatro proyectos de ley diferentes todas esas materias. En concreto, la aprobación del relativo a los estados excepcionales, que había quedado un tanto descuidado, se retomó con gran celeridad tras el intento de golpe de estado de 23 de febrero de 1981 y los graves atentados terroristas que tuvieron lugar al mes siguiente. De esta forma, el proyecto, tramitado por el procedimiento de urgencia, fue aprobado el 20 de mayo con un amplísimo respaldo de los diputados (266 votos a favor, 7 en contra y 21 abstenciones), y promulgado y sancionado el 1 de junio como Ley Orgánica 4/1981, de 1 de junio, de los estados de alarma, excepción y sitio ${ }^{26}$.

Según hemos podido comprobar a través de este rápido repaso de la evolución del derecho de excepción en la historia de nuestro constitucionalismo, la expresión "estado de alarma", antes de la Constitución de 1978, había sido empleada tan solo en dos ocasiones: en la Ley de Orden Público de 1870, que lo vinculaba en una misma perífrasis al "estado de prevención", y, de manera singular, en la Ley de 1933. En ambos casos, la declaración de dicho estado conllevaba la suspensión de ciertos derechos y garantías, por lo que, en realidad, podríamos más bien considerarlos precedentes del estado de excepción actual. De este modo, cabría entender que el precedente más directo del actual "estado de alarma" es, en realidad, el llamado "estado de prevención" de la Ley de 1933, "que aparecía como un primer grado de situación excepcional del orden público en el que determinados derechos y

\footnotetext{
${ }^{25}$ Pues previamente, como acabamos de ver, solo es posible encontrar una mínima referencia al "estado de guerra" en la Constitución de 1931 (art. 95 párr. 3o).

${ }_{26}^{2}$ Un resumen detallado de este proceso en FERNÁNDEZ SEGADO, F., "La Ley Orgánica..., pp. 83 ss.
} 
libertades son sometidos a un régimen particularmente restrictivo, que no llega, sin embargo, a la suspensión"27. Conviene retener este último dato, pues, pese a tratarse tan solo de un precedente, con el valor hermenéutico relativo que ello tiene, puede resultar de interés cuando tratemos de desentrañar la naturaleza del estado de alarma mencionado en el art. 116 CE y desarrollado en la LOAES.

\section{Las disposiciones comunes a los tres estados excepcionales}

El Capítulo Primero de la LOAES, que contiene las disposiciones comunes a los estados de alarma, excepción y sitio, comienza con la declaración de un principio general cuya relevancia no se puede ignorar, pues constituye la condición ineludible que habilita la declaración de cualquiera de estos estados. En efecto, el art. 1.1 LOAES dispone explícitamente que "[p]rocederá la declaración de los estados de alarma, excepción o sitio cuando circunstancias extraordinarias hiciesen imposible el mantenimiento de la normalidad mediante los poderes ordinarios de las Autoridades competentes". El uso de los adjetivos, en este caso, resulta sustantivo. En primer lugar, porque la propia ley apela a la concurrencia no de cualquier circunstancia, sino de unas que califica de "extraordinarias" (es decir, imprevistas e imprevisibles; o de un alcance, envergadura o gravedad que sobrepase los límites de lo que podría considerarse normal o habitual; etc.). $Y$, en segundo término, y esto quizás tenga aún más importancia a los efectos que aquí nos interesa, porque tales circunstancias han de hacer "imposible" mantener la normalidad mediante la actuación de los poderes "ordinarios" de las autoridades "competentes". Es decir, la LOAES parte del presupuesto de que siempre que sea posible se ha de hacer frente a las circunstancias sobrevenidas, por muy graves 0 extraordinarias que sean, acudiendo a la actuación de los poderes ordinarios ejercidos por las autoridades competentes. Solo si ello resultara "imposible" estaría justificado activar los poderes extraordinarios que la Constitución prevé en el art. 116 y la LOAES desarrolla, asumiendo que ello puede traer consigo un reforzamiento de las facultades de una autoridad que, en circunstancias ordinarias, no sería la competente (ya pensemos en la distribución horizontal o vertical del poder). En definitiva, este primer apartado del artículo primero de la

${ }^{27}$ CRUZ VILLALÓN, P., Estados excepcionales..., p. 67. 
LOAES acentúa el carácter radicalmente subsidiario (ultima ratio) ${ }^{28}$ del derecho de excepción, al que solo se podrá acudir cuando no sea posible ofrecer una respuesta a la situación sobrevenida por parte de las autoridades competentes aplicando el derecho ordinario.

En lógica coherencia con lo previsto en el apartado 1 que acabamos de comentar, el apartado siguiente (2) del art. 1 LOAES dispone que "[l]as medidas a adoptar en los estados de alarma, excepción y sitio, así como la duración de los mismos, serán en cualquier caso las estrictamente indispensables para asegurar el restablecimiento de la normalidad". No parece que esta disposición ofrezca demasiadas dudas interpretativas. De ella cabe derivar claramente que el objetivo único con la declaración de alguno de estos estados es restablecer cuanto antes la normalidad que se ha visto gravemente alterada $^{29}$, esto es, volver a la aplicación del derecho ordinario por parte de las autoridades competentes ${ }^{30}$. Algo que deberán tener muy en cuenta los responsables de la declaración de estos estados a la hora de fijar el plazo de duración de los mismos o de sus prórrogas, lo que resulta especialmente relevante en relación con la determinación de la duración de la prórroga del estado de alarma, dada la indefinición constitucional y legal ${ }^{31}$.

${ }^{28}$ CARRO MARTíNEZ, A., "Artículo 116...", p. 214.

${ }^{29}$ FERNÁNDEZ SEGADO, F., "La Ley Orgánica..., pp. 92-93.

${ }^{30}$ En palabras de Solozábal, "la restauración constitucional determina la justificación del estado excepcional" (SOLOZÁBAL ECHAVARRÍA, J. J., "Algunas consideraciones constitucionales..., pp. 3-4).

${ }^{31}$ De las cuatro experiencias habidas hasta el momento (la de diciembre de 2010 en relación con la huelga encubierta de los controladores aéreos y las de marzo, septiembre y octubre de 2020 en relación con la pandemia de Covid-19) cabe deducir que, en relación con la primera y la última, el Gobierno y el Congreso han interpretado la duración de la prórroga con cierta ligereza. En el primer caso porque de manera discutible se estableció en casi 30 días, cuando una interpretación sistemática del art. 116.2 CE parece aconsejar que la misma haya de ser de 15 días como máximo (en coherencia con lo previsto en relación con el estado de excepción, cuya declaración y prórroga es coincidente: 30 días); y, sobre todo, en el último porque parece evidente que supone un exceso fijar aquella en 6 meses, no solo por la razón que acabamos de apuntar (interpretación sistemática del apartado 2 del art. $116 \mathrm{CE}$ en relación con el apartado 3), que es la principal, sino porque además se retuerce la previsión del art. 1.2 LOAES, que, como acabamos de ver, dispone que dicho plazo ha de ser el "estrictamente indispensable para asegurar el restablecimiento de la normalidad". Sea como fuere, lo que parece fuera de toda duda es que si se superase la situación extraordinaria estando vigente algún estado excepcional (ya sea desde su primera declaración, ya sea como consecuencia de la prórroga autorizada por el Congreso), habrá de procederse con carácter inmediato a su levantamiento, simple y llanamente porque solo así se podrá cumplir de modo pleno y coherente con el objetivo que a través de dichos estados se persigue: restablecer la normalidad.

En otro lugar he defendido, no sin ciertas prevenciones, pues me parece una interpretación ciertamente un tanto forzada del apartado 2 del art. 116 CE en relación con el apartado 3 del mismo, aunque quizás no del todo imposible, que "por una mera razón de coherencia intrasistémica en el ámbito del derecho de excepción, la prórroga del estado de alarma no 
El art. 1.2 in fine LOAES contiene también un mandato relevante: que la aplicación de las medidas extraordinarias que se adopten habrá de realizarse "de forma proporcionada a las circunstancias". Cabría entender que aquí resulta aplicable el test de proporcionalidad, característico del ámbito de los derechos fundamentales ${ }^{32}$; esto es, exigir que las medidas sean idóneas o adecuadas para hacer frente a las circunstancias extraordinarias; que sean además necesarias, es decir, que no existan otras menos graves o invasivas con las que se pueda alcanzar el mismo resultado; y que sean proporcionales en sentido estricto, en tanto que el perjuicio que con ellas se causa no es superior al beneficio que gracias a ellas se obtiene ${ }^{33}$.

Este primer artículo de la LOAES, que sienta algunos de los principios generales aplicables a todos los estados excepcionales, contiene asimismo un apartado 3 en el que, partiendo del necesario carácter temporal de todos ellos, preceptúa que, como es natural, finalizada su vigencia "decaerán en su eficacia cuantas competencias en materia sancionadora y en orden a actuaciones preventivas correspondan a las Autoridades competentes, así como las concretas medidas adoptadas en base a estas, salvo las que consistiesen en sanciones firmes".

Finalmente, el apartado 4, reitera prácticamente en su literalidad lo dispuesto en el art. 116.5 CE, a saber, que "[l]a declaración de los estados de alarma, excepción y sitio no interrumpe el normal funcionamiento de los poderes constitucionales del Estado". Esta insistencia del legislador pone de relieve la

puede exceder el plazo máximo previsto para la prórroga del estado de excepción, es decir, treinta días". En todo caso, lo que parece claro a todas luces es que, como ha sido ya dicho, una prórroga de seis meses constituye un exceso de imposible justificación (ARROYO GIL, A., ¿Estado de alarma sin control?", Agenda Pública, 28.10.2020 http://agendapublica.elpais.com/estado-de-alarma-sin-control/).

${ }^{32}$ Lo que no tiene por qué extrañar, pues en el campo de los estados excepcionales, como hemos visto, lo que puede estar en juego es, entre otras cosas, una grave afectación, e, incluso, suspensión de ciertos derechos fundamentales.

${ }^{33}$ Vid. ÁLVAREZ GARCÍA, V., "El coronavirus (COVID-19): respuestas jurídicas frente a una situación de emergencia sanitaria", El Cronista del Estado Social y Democrático de Derecho, $86-87,2020$, pp. 8 y 11, quien recuerda, con toda razón, que "el principio de proporcionalidad no sólo entra en juego a la hora de decidir (o no) la declaración del estado de alarma, sino que rige su duración y todas y cada una de las concretas medidas de necesidad que se adopten durante su vigencia".

Sobre la necesidad de prevenir los posibles abusos (judiciales) a partir de una aplicación desmedida de esta cláusula, vid. SOLOZÁBAL ECHAVARRÍA, J. J., "Algunas consideraciones constitucionales..., pp. 5 ss.

Sobre la virtualidad del test de proporcionalidad en relación con la declaración del estado de alarma en marzo de 2020, vid. ARROYO GIL, A., "¿Estado de alarma o estado de excepción?", Agenda Pública, 12.04.2020 (http://agendapublica.elpais.com/estado-de-alarma-o-estado-deexcepcion/). 
importancia que el mismo le da al hecho de que quede despejada cualquier duda posible sobre la permanencia de los órganos constitucionales y el ejercicio que los mismos hacen de sus facultades, más allá de que la normativa de excepción transitoriamente pueda traer consigo, según se ha señalado ya, un reforzamiento del papel de los órganos ejecutivos ( $\mathrm{y}$, en especial, del Gobierno central) en detrimento de las facultades de los órganos legislativos y de las competencias de las Comunidades autónomas ${ }^{34}$. No es preciso volver a insistir sobre las dudas que esto plantea en relación con la incidencia en el sistema de distribución y delimitación de competencias ${ }^{35}$, a partir de una previsión constitucional tan abierta como lo es la contenida en el art. $116 \mathrm{CE}$.

Por su parte, el art. 2 LOAES se refiere a la obligación de publicar con la mayor celeridad posible ("de inmediato") en el BOE la declaración de cualquiera de los estados excepcionales y de difundirla "por todos los medios de comunicación públicos y por los privados que se determinen", dado que la misma "entrará en vigor desde el instante mismo de su publicación en aquel". Parece lógico el empeño del legislador por acelerar la publicación y difusión de la declaración, ya que la activación de cualquiera de estos estados viene motivada precisamente por la necesidad de ofrecer una respuesta rápida y efectiva a unas circunstancias extraordinarias que no se pueden afrontar debidamente haciendo uso de los medios y procedimientos ordinarios, de por sí, más lentos y pesados. $Y$ resulta preciso, a tal efecto, que dicha declaración sea conocida por todos los afectados por la misma. Obligación de difusión que atañe también, por la misma razón, a "las disposiciones que la Autoridad competente dicte durante la vigencia de cada uno de dichos estados".

Por último, el art. 3 LOAES, en su apartado primero, despeja cualquier duda posible sobre la impugnabilidad en vía jurisdiccional de los actos y disposiciones de la Administración pública durante la vigencia de los estados de alarma, excepción y sitio, de conformidad con lo dispuesto en las leyes. Queda así claro que la Administración, por más que pueda disponer de amplios márgenes de discrecionalidad en la ejecución de las medidas aprobadas por el

${ }^{34}$ A tal efecto, Vicente Álvarez señala que "[u]na de las características del Derecho de necesidad es que se modifican, como regla general, las reglas normales de reparto de competencias, procediéndose en los casos verdaderamente severos a su concentración en manos de una autoridad ejecutiva", a fin de buscar "una unidad tanto de decisión política como de gestión administrativa que hago lo más eficaz y coordinada posible la lucha contra la crisis" (ÁLVAREZ GARCÍA, V., "El coronavirus..., p. 16).

${ }_{35}$ Un estudio del mismo en ARROYO GIL, A., Distribución y delimitación de competencias, Debates constitucionales, Marcial Pons-Fundación Manuel Giménez Abad, Madrid, 2019. 
Gobierno o el Congreso de los Diputados para hacer frente a la situación extraordinaria de que se trate en cada caso, no se mueve, sin embargo, en un terreno libre de Derecho, sino que su actuación está sujeta al control jurisdiccional correspondiente, tal y como, por otro lado, la Constitución, en su art. 116.6 CE ya se había encargado de señalar, según vimos con anterioridad, en relación con "el principio de responsabilidad del Gobierno y de sus agentes".

Finalmente, el apartado segundo de este art. 3 LOAES se dedica a asegurar el mantenimiento del principio de responsabilidad civil de la Administración al disponer que "[q]uienes como consecuencia de la aplicación de los actos y disposiciones adoptadas durante la vigencia de estos estados sufran, de forma directa, o en su persona, derechos o bienes, daños o perjuicios por actos que no les sean imputables, tendrán derecho a ser indemnizados de acuerdo con lo dispuesto en las leyes".

\section{III.NATURALEZA DEL ESTADO DE ALARMA}

Como sabemos ya, el estado de alarma es, junto con los estados de excepción y sitio, uno de los estados excepcionales a que se refiere el art. $116 \mathrm{CE}$. Aunque de la literalidad de este precepto no se deriva necesariamente una distinta naturaleza del estado de alarma y el de excepción ${ }^{36}$ (cosa que sí cabría deducir en relación con el estado de sitio, dada la posible vinculación que el art. 117.5 CE establece entre el mismo y la jurisdicción militar), lo cierto es que la ley orgánica que los regula, con carácter configurador, sí parece partir de una diferencia sustancial entre uno y otro. Así, mientras que el estado de alarma parece estar pensado fundamentalmente para hacer frente a situaciones derivadas de hechos naturales o tecnológicos, 0 accidentes graves, que pueden poner en serio riesgo la vida o la seguridad de las personas, el estado de excepción, por el contrario, ofrece una respuesta a situaciones de naturaleza eminentemente política que pueden provocar una grave alteración del orden público ${ }^{37}$.

\footnotetext{
${ }^{36}$ Otra cosa es que, como señala CRUZ VILLALÓN, P., Estados excepcionales..., pp. 66 ss., de los debates constituyentes sí quepa derivar con más claridad la intención de "despolitizar" el estado de alarma, y que de los debates parlamentarios habidos durante la tramitación del proyecto de LOAES se derive igual conclusión. En la misma línea, SIEIRA MUCIENTES, S., "Estado de alarma"..., p. 276.

${ }^{37}$ A este respecto, FERNÁNDEZ SEGADO, F., "La Ley Orgánica..., pp. 95 ss., aunque asume la certeza de esta diferenciación, admite, sin embargo, que, dada la ambigüedad y vaguedad del texto constitucional, el estado de alarma podría declararse también "frente a ciertos tipos de conflictividad social que no exigieran la suspensión de garantías, e incluso frente a algún
} 
Sin perjuicio de que veamos más adelante cada uno de los supuestos en que de conformidad con el art. 4 LOAES cabe declarar el estado de alarma, interesa adelantar desde ya mismo que dos de ellos, en concreto los previstos en los apartados c) y d), proyectan cierta sombra de duda sobre la completa certeza de la aseveración anterior: que el estado de alarma está previsto para hacer frente a situaciones graves derivadas de hechos naturales o accidentes, mientras que el estado de excepción sirve para dar una respuesta a situaciones igualmente graves de alteración del orden público de origen político. Y es que, en efecto, nada impediría entender que la "[p]aralización de servicios públicos esenciales para la comunidad" o las "[s]ituaciones de desabastecimiento de productos de primera necesidad", a que se refieren dichos apartados c) y d) del art. 4 LOAES, podrían derivar de una crisis política o social grave que supusiese una seria alteración del orden público ${ }^{38}$.

En relación con el primero de estos supuestos, el previsto en la letra c), tal duda no quedaría desmentida con la primera condición que impone este mismo apartado más adelante ("cuando no se garantice lo dispuesto en los artículos veintiocho, dos, y treinta y siete, dos, de la Constitución"), en la medida en que lo que no quedaría garantizado sería precisamente "el mantenimiento de los servicios esenciales de la comunidad", según el primero de estos preceptos, o, en términos muy similares, "el funcionamiento de los servicios esenciales de la comunidad", de conformidad con el segundo de ellos. Ahora bien, la segunda condición que impone el susodicho apartado c) del art. 4 LOAES debilita la posibilidad de una interpretación como la que nos estamos cuestionando, en la medida en que la referida "paralización de servicios públicos esenciales para la comunidad" solo servirá como supuesto habilitante de la declaración del estado de alarma si concurre "alguna de las demás circunstancias o situaciones contenidas en este artículo". Dicho de otra manera, la paralización de los

supuesto de conflictividad político-social". Precisamente, el art. 20 del Proyecto de ley de seguridad ciudadana apuntaba en esa dirección, si bien, posteriormente, a través de enmiendas, iba a desaparecer tal perspectiva. Vid. asimismo CRUZ VILLALÓN, P., Estados excepcionales..., p. 52.

A favor de la naturaleza no política de las circunstancias que puedan motivar la declaración de un estado de alarma, a diferencia de lo que sucede claramente con el estado de excepción, se han pronunciado la mayor parte de los autores. Vid., entre otros, ABA CATOIRA, A., "El estado de alarma..., pp. 326, 330; y REQUEJO RODRÍGUEZ, P., "Teoría vs. práctica del estado de alarma en España", en VV.AA., Constitución y democracia. Ayer y hoy, libro homenaje a Antonio Torres del Moral, vol. 2, Universitas, Madrid, 2012, p. 1500.

${ }^{38}$ GARRIDO LÓPEZ, C., "La naturaleza bifronte..., p. 379. 
servicios esenciales para la comunidad no constituye un supuesto autónomo o individualizado, sino que se encuentra indisolublemente ligado a los demás supuestos previstos en los apartados a), b) y d) ${ }^{39}$. Por lo que se refiere a los de los apartados a) y b), que veremos después con más detalle, solo adelantaremos aquí que los mismos apuntan claramente hacia situaciones naturales o accidentes, de modo que la afirmación sobre la diferente naturaleza de los estados de alarma y excepción no quedaría en entredicho; sin embargo, el supuesto del apartado d) vuelve a introducir alguna sombra de duda al respecto, pues al referirse a "[s]ituaciones de desabastecimiento de productos de primera necesidad", podría darse el caso de que estas vinieran también motivadas por una crisis de orden político o un conflicto social grave que acarrease esa consecuencia fatal ${ }^{40}$.

En definitivas cuentas, podemos concluir, con carácter provisional, que mientras que la declaración del estado de alarma principalmente vendrá motivada por la concurrencia de una serie de hechos naturales o tecnológicos, o accidentes, que supongan una grave alteración de la normalidad, por su parte, la del estado de excepción derivará de graves crisis de orden público de naturaleza eminentemente política o social, existiendo una zona de confluencia entre ambos estados, en la medida en que en los dos se prevé la posibilidad de su declaración para hacer frente a situaciones sustancialmente idénticas: una paralización de servicios esenciales para la comunidad acompañada de desabastecimiento de productos de primera necesidad, o esta última situación por sí sola (art. 4.c) y d) LOAES); o una grave alteración del normal funcionamiento de los "servicios públicos esenciales para la comunidad" (art. 13.1 LOAES). Nada impide entender que tanto en el caso del estado de excepción, como en el de alarma, dichas situaciones puedan venir motivadas por una crisis política o social grave ${ }^{41}$. A esta hermenéutica coadyuvaría el

${ }^{39}$ Esto es lo que Ileva a Pedro Cruz a entender que este 'tercer supuesto' queda en una
situación bastante peculiar, reducido "prácticamente a un no-supuesto", en la medida en que
"la paralización de servicios públicos esenciales no puede dar lugar nunca, por sí sola, a una
declaración del estado de alarma, sino solo cuando dicha paralización coincida con alguno de
los otros supuestos restantes. Pero si se dan éstos el estado de alarma puede ser declarado,
siendo indiferente el que además se produzca el supuesto descrito en la letra C). La segunda
adición incorporado al supuesto c) equivalía así a su supresión" (CRUZ VILLALÓN, P., Estados
excepcionales..., p. 70).
${ }^{40}$ Vid. BERDUGO GÓMEZ DE LA TORRE, I.: "Los estados de alarma, excepción y sitio:
Comentario a la Ley Orgánica 4/1981 de 1 de junio", Revista de Política Comparada, 5 , p. 105.
${ }^{41}$ No llega a esta conclusión el profesor Cruz, para quien "la interpretación más coherente del
estado de alarma es la que excluiría del mismo las situaciones de conflictividad social graves,
que encontrarían su lugar en el estado de excepción (...). Las situaciones de
desabastecimiento del estado de alarma deberían ser entendidas, en coherencia con el resto 
hecho de que el apartado c) del art. 11 LOAES disponga que, entre las medidas que puede adoptar el decreto de declaración del estado de alarma, o los sucesivos que se dicten durante su vigencia, se encuentra "[i]ntervenir y ocupar transitoriamente industrias, fábricas, talleres, explotaciones o locales de cualquier naturaleza, con excepción de domicilios privados, dando cuenta de ello a los Ministerios interesados"; o que el apartado e) de este mismo precepto mencione la siguiente: "Impartir las órdenes necesarias para asegurar el abastecimiento de los mercados y el funcionamiento de los servicios de los centros de producción afectados por el apartado d) del artículo cuarto". Tanto en un caso como en el otro da la impresión de que el legislador orgánico entiende que también cabría declarar el estado de alarma para dar una respuesta a situaciones extraordinarias derivadas de conflictos sociales graves. A esa misma interpretación nos podría llevar la lectura del art. 12.2 LOAES, que establece que "[e]n los casos previstos en los apartados c) y d) del artículo cuarto el Gobierno podrá acordar la intervención de empresas o servicios, así como la movilización de su personal, con el fin de asegurar su funcionamiento. Será de aplicación al personal movilizado la normativa vigente sobre movilización que, en todo caso, será supletoria respecto de lo dispuesto en el presente artículo". Y es que más allá de lo que pueda significar en este contexto el término "movilización", lo cierto es que también estas medidas extraordinarias que puede adoptar el Gobierno parecen estar pensadas para ofrecer una respuesta a una situación de conflictividad social grave ${ }^{42}$.

Así pues, habrá que admitir que, si se dan las circunstancias a las que nos hemos referido anteriormente, será posible declarar uno u otro estado en

de supuestos, como situaciones originadas en causas naturales o en crisis internacionales" (CRUZ VILLALÓN, P., Estados excepcionales..., pp. 71-72). En definitiva, "el legislador ha efectuado una 'despolitización' del estado de alarma, dejándolo al margen de las situaciones de desorden público o conflictividad social, para destinarlo a combatir las catástrofes naturales 0 tecnológicas"; porque "las crisis de orden público se hallan confinadas al estado de excepción" (CRUZ VILLALÓN, P., "El nuevo derecho de excepción (Ley Orgánica 4/1981, de 1 de junio), Revista Española de Derecho Constitucional, 2, 1981, pp. 99 y 100).

De otra opinión, SOLOZÁBAL ECHAVARRÍA, J. J., "Algunas consideraciones constitucionales..., pp. 7 y 11, quien sin negar que la situación de emergencia que puede dar lugar a la declaración del estado de alarma carece de "raíz política o constitucional", entiende, sin embargo, que la misma puede proceder de un caso de "conflictividad social extremada" que conlleve un desabastecimiento o una paralización de los servicios esenciales; "puede suceder (...) que la crisis contemplada a priori en el estado de alarma se convierta en una quiebra del orden público, teniendo en cuenta que, de otro lado, el propio estado de alarma, sobre todo si atendemos a la jurisprudencia del Tribunal Constitucional, puede entenderse también desde la perspectiva del orden público (...) (STC 66/1995)".

${ }_{42}$ Tal y como reconoce el propio Pedro Cruz, pionero defensor de la distinta naturaleza de uno y otro estados (CRUZ VILLALÓN, P., Estados excepcionales..., pp. 78-79). 
función de que se considere preciso solo limitar o restringir (estado de alarma) o también suspender (estado de excepción) ciertos derechos fundamentales (los previstos en el art. $55.1 \mathrm{CE})^{43}$, sin que ello desmienta el principio general mencionado anteriormente: que el estado de alarma está fundamentalmente pensado para dar respuesta a situaciones extraordinarias derivadas de hechos naturales o tecnológicos, o accidentes graves, mientras que el estado de excepción representa una solución para las situaciones de grave alteración del orden público originadas por crisis políticas o sociales severas ${ }^{44}$.

\section{SUPUESTOS DE DECLARACIÓN DEL ESTADO DE ALARMA}

Tal y como se ha apuntado supra, la Constitución no establece cuáles son los hechos 0 circunstancias extraordinarias que se han de producir ${ }^{45}$ para que quepa declarar alguno de los estados excepcionales que la misma prevé, incluido, el de alarma ${ }^{46}$. Esto es algo que hace la ley orgánica reguladora de los

\footnotetext{
${ }^{43}$ Vid. GARCÍA CUADRADO, A. M.: "El estado de alarma y su ambigua naturaleza", Cuadernos de la Cátedra Fadrique Furió Ceriol, 8, 1994, p. 85. Por su parte, FERNÁNDEZ SEGADO, F., "La Ley Orgánica..., p. 101, tras analizar el proyecto del Gobierno, el Informe de la Ponencia y las enmiendas aceptadas durante la tramitación del procedimiento legislativo que concluyó en la aprobación de la LOAES, sostiene que "el estado de excepción no implica el agravamiento de los supuestos previstos para el estado de alarma, sino que su naturaleza es de un orden diferente y esencialmente político-social". No reconoce, al menos explícitamente, la posibilidad de que se pueda dar una zona de confluencia entre ambos estados, tal y como defendemos aquí.

${ }^{44}$ Para CRUZ VILLALÓN, P., Estados excepcionales..., p. 80, el problema básico del estado de alarma "es que no parece adecuado ni para enfrentarse con éxito a las catástrofes naturales 0 tecnológicas ni a las situaciones de conflictividad social", a lo que se ha de añadir el hecho de que "la legislación específica sobre sanidad, incendios, etc. a que se refiere el artículo 12.1 de la Ley orgánica suele contemplar ya las medidas contenidas en el artículo 11 de la misma, con la ventaja de que no es preciso acudir a las formalidades propias de la declaración de un estado excepcional".

${ }^{45}$ Es discutible que se pueda declarar un estado excepcional con carácter preventivo. Con carácter general, lo niega REQUEJO RODRíGUEZ, P., "Teoría vs. práctica del estado de alarma..., p. 1510. En relación con el estado de alarma, lo afirma ALZAGA VILLAAMIL, Ó.: Comentario sistemático a la Constitución española de 1978, Marcial Pons, Madrid, 2a ed., Madrid, 2016, p. 533.

${ }^{46}$ Por ese motivo, Cruz Villalón ha sostenido que el art. 116 CE es un precepto 'incompleto', porque "le faltaba un elemento tan fundamental para la aplicación de cualquiera de estos estados como es el presupuesto de hecho habilitante, es decir, la determinación de la situación de emergencia a la que, con cada uno de ellos, se pretendía hacer frente" (CRUZ VILLALÓN, P., Estados excepcionales..., pp. 61-62). O, dicho de otro modo, es la entrada en vigor de la LOAES lo que hace al derecho constitucional de excepción "un derecho inmediatamente aplicable" (CRUZ VILLALÓN, P., "El nuevo derecho de excepción..., p. 94). En el mismo sentido, GARRIDO LÓPEZ, C., "La naturaleza bifronte..., p. 375.

Sin negar la razón de la denuncia de dicha ausencia, tal vez resulte un tanto excesivo calificar de 'incompleto' a este precepto constitucional. Y es que, más allá de las dificultades de concreción que derivarían de esa ausencia, sí cabría imaginar que, de haber sido preciso, se
} 
mismos. A tal efecto, el art. 4 LOAES, en relación con el estado de alarma, dispone lo siguiente:

"El Gobierno, en uso de las facultades que le otorga el artículo ciento dieciséis, dos, de la Constitución podrá declarar el estado de alarma, en todo o parte del territorio nacional, cuando se produzca alguna de las siguientes alteraciones graves de la normalidad:

a) Catástrofes, calamidades o desgracias públicas, tales como terremotos, inundaciones, incendios urbanos y forestales o accidentes de gran magnitud.

b) Crisis sanitarias, tales como epidemias y situaciones de contaminación graves.

c) Paralización de servicios públicos esenciales para la comunidad, cuando no se garantice lo dispuesto en los artículos veintiocho, dos, y treinta y siete, dos, de la Constitución, concurra alguna de las demás circunstancia o situaciones contenidas en este artículo.

d) Situaciones de desabastecimiento de productos de primera necesidad".

Solo si se da, por tanto, alguno de estos supuestos podrá el Gobierno declarar el estado de alarma, mediante decreto acordado por el Consejo de Ministros, por un plazo máximo de quince días, dando cuenta al Congreso de los

hubiese podido aplicar directamente la previsión del art. $116 \mathrm{CE}$ declarando cualquiera de los estados que el mismo prevé. Lógicamente, el Gobierno y el Congreso hubiesen gozado de un margen de discrecionalidad mucho más amplio del que ostentan tras la aprobación de la ley; pero ese solo hecho no implica, per se, una imposibilidad de declarar el estado correspondiente si las circunstancias lo hubieran demandado. $Y$ es que no parece que tenga demasiado sentido sostener que el Estado, a través de sus órganos constitucionales correspondientes, haya de permanecer inerme ante situaciones extraordinarias que demandan una respuesta urgente y excepcional por el solo hecho de que no exista desarrollo legal de una previsión constitucional que a lo que apunta, precisamente, es a la legitimidad de aquellas medidas que sean necesarias para dar una respuesta a una crisis (natural, política, social o de orden constitucional) que puede poner en riesgo la seguridad de las personas, del conjunto de la comunidad o del Estado mismo. Quizás en pocos momentos como este tenga sentido traer a colación la máxima de Ciceron salus populi suprema lex esto (De legibus, III, 3, 8), sin que ello signifique, lógicamente, descuidar el principio de prudencia en su aplicación y, en todo caso, el respeto de los derechos fundamentales. Vid. Farrés Juste, O.: "Salus populis suprema lex", Revista de Bioética y Derecho, 50, 2020, pp. 5-17. Como señala Antonio Carro, que el poder se mantenga neutral ante ciertos excesos o anormalidades es una mera posibilidad teórica; precisamente "en Alemania y en Italia, donde las respectivas Constituciones carecían de previsiones expresas sobre la excepcionalidad constitucional, la doctrina ha interpretado este silencio en sentido positivo; es decir, que la emergencia exige actuaciones extraordinarias del poder por razones de necesidad"; lo que, curiosamente, no obsta para que sostenga que el art. 116 CE resultaba inaplicable sin el concurso de la ley orgánica que había de desarrollarlo (CARRO MARTíNEZ, A., "Artículo 116..., pp. 213 y 250). 
Diputados, completándose, de este modo, la falta de previsión del art. 116.2 CE. Más allá de la generalidad con que vienen formulados algunos de los supuestos, dentro de los cuales cabe imaginar muy distintas circunstancias concretas, lo cierto es que la enumeración es exhaustiva, sin que quepa, por tanto, ampliar su número. A esta conclusión conduce no solo la literalidad de su enunciado, sino también la crónica de su tramitación parlamentaria, pues en la redacción del Dictamen se disponía con carácter más abierto -ejemplificativo, en realidad- la relación de supuestos ("...cuando se produzcan alteraciones graves de la normalidad como las siguientes..."), pero a través de enmiendas presentadas por los Grupos vasco y comunista, y finalmente, por medio de la transaccional propuesta por el Grupo de UCD, se reformuló su redacción para suprimir cualquier posibilidad de ampliación de dicho número de supuestos ${ }^{47}$.

Sin perjuicio de que seguidamente hagamos referencia a cada uno de ellos, y al margen de lo ya dicho con anterioridad en el apartado relativo a la naturaleza del estado de alarma al analizar el contenido de los apartados c) y d), parece claro, como señalábamos entonces, que este estado está pensado básicamente para ofrecer una respuesta excepcional a situaciones extraordinarias derivadas de hechos naturales o accidentes que alteren gravemente la normalidad. Lo que se vería además corroborado por el hecho de que en el proyecto originario se incluía también como supuesto habilitante ciertas alteraciones del orden o seguridad que finalmente acabaron desapareciendo, fundamentalmente como consecuencia de la oposición socialista $^{48}$.

Sin embargo, más allá de que la tramitación parlamentaria de la LOAES (y, anteriormente, del frustrado proyecto de ley de seguridad ciudadana), apuntaran en esa dirección (privar al estado de alarma de cualquier connotación política o social), la cuestión no quedó del todo zanjada, en la medida en que, finalmente, dos de los supuestos habilitantes, los mencionados en las letras c) y d) del art. 4 LOAES, permiten entender, como hemos visto ya,

\footnotetext{
${ }^{47}$ Vid. ABA CATOIRA, A., "El estado de alarma..., pp.. 331-332.

${ }^{48}$ Vid. CARRO MARTíNEZ, A., "Artículo 116..., p. 253, para quien, "[p]rivado el estado de alarma de las singularidades propias del orden público, ha pasado a ser algo anodino y de naturaleza totalmente distinta a los estados de excepción y sitio"; lo que le lleva a concluir que "[e]n puridad, el estado de alarma y la nada son la misma cosa, porque las facultades de la autoridad son las mismas que le corresponden en período de normalidad". En coherencia con lo que se viene manteniendo a lo largo del texto, no se puede compartir aquí tan tajante conclusión.
} 
que este estado excepcional tiene una naturaleza doble ${ }^{49}$ (la principal: para hacer frente a situaciones extraordinarias que traen causa de hechos naturales o tecnológicos, o de accidentes; y la secundaria: para dar respuesta a determinadas crisis sociales o políticas que puedan traer consigo la paralización de servicios públicos esenciales para la comunidad junto a situaciones de desabastecimiento de productos de primera necesidad, o solo estas últimas, y que no precisen de una declaración del estado de excepción, porque no sea preciso proceder a la suspensión de alguno de los derechos previstos en el art. 55.1 CE).

Centrándonos ya en cada uno de los supuestos a que se refiere este art. 4 LOAES, comprobamos que el previsto en el apartado a) hace referencia claramente a situaciones graves ("Catástrofes, calamidades o desgracias públicas") provocadas por hechos naturales o accidentes ("tales como terremotos, inundaciones, incendios urbanos y forestales o accidentes de gran magnitud"). Este es el presupuesto que mejor encajaría con un entendimiento del estado de alarma como estado excepcional cualitativamente distinto del estado de excepción ( $y$, lógicamente, también de sitio), porque, en principio, las situaciones a que se refiere carecen de un evidente componente político y/o social. Antes bien, lo relevante aquí es la dimensión (grave, imprevisible o imprevista) del hecho o del accidente, que lo haría inabordable mediante la utilización de los medios legales ordinarios por su falta de eficacia. Es esa magnitud lo que justificaría, por tanto, la declaración del estado de alarma. Ahora bien, aun siendo esto así, tampoco se puede ignorar que cualquiera de esas catástrofes, calamidades o desgracias públicas causadas por hechos naturales (terremotos, inundaciones, incendios urbanos y forestales) 0 accidentes de gran magnitud (como podría ser, por ejemplo, una explosión de gas o en una central nuclear) puede acabar derivando en una grave crisis política y/o social, susceptible de poner en riesgo el mantenimiento del orden público $^{50}$. Si eso sucediera no habría por qué acudir automáticamente a la

\footnotetext{
${ }^{49}$ En esta línea, Carlos Garrido, entiende que el estado de alarma ha quedado finalmente configurado como "un estado excepcional sui generis de ambigua naturaleza" (GARRIDO LÓPEZ, C., "La naturaleza bifronte..., p. 378).

${ }^{50}$ En este sentido, José Julio Fernández, pese a sostener que los tres estados excepcionales previstos en el art. 116 CE están diseñados para "circunstancias diferentes, no intercambiables y no conectadas", admite que es posible "que la realidad problemática vaya mudando y pase del objeto de un estado al de otro (por ejemplo, una crisis se convierte en un problema de orden público"). Vid. FERNÁNDEZ RODRÍGUEZ, J. J.: "Cuestiones constitucionales sobre el estado de alarma en España y la pandemia del COVID-19", Documento de Opinión (ieee.es), 43, 2020 , p. 8.
} 
declaración del estado de excepción, salvo que la respuesta demandara la suspensión de alguno de los derechos previstos en el art. 55.1 CE.

Por su parte, el apartado b) se refiere también a una emergencia ("crisis sanitaria"), ejemplificándola en las "epidemias y situaciones de contaminación graves", que, lógicamente, podría ser consecuencia de hechos naturales (por ejemplo, un virus de origen animal que se transmita al ser humano, o un incendio provocado por un rayo que genere una aguda contaminación atmosférica), de accidentes (en un laboratorio en el que se manipulan organismos vivos transmisores de algún virus, o en una central nuclear, por ejemplo) o de la acción del ser humano (como sucede, entre otros muchos casos, con la contaminación de la atmósfera por la generación excesiva de dióxido de carbono). Como resulta evidente, también todos estos casos, pese a su origen natural o accidental, podrían acabar desembocando en una crisis política o social grave, que incluso podría acarrear una seria alteración del orden público. $\mathrm{Y}$ al igual que en el supuesto anterior, cabría la posibilidad de que las medidas a tomar para afrontar esa situación no requiriesen ineludiblemente la suspensión de alguno de los derechos previstos en el art. 55.1 CE, en cuyo caso no sería preciso proceder a la declaración del estado de excepción, bastando, pues, con la declaración o, en su caso, prórroga, del estado de alarma.

Por lo que se refiere a los apartados c) y d), me remito a lo dicho más arriba en relación con la naturaleza del estado de alarma. Si acaso, recordar tan solo que es precisamente en estos supuestos en donde se pone más de relieve la naturaleza mixta de este estado excepcional, una herramienta constitucional dotada de una importante dosis de ductilidad, que puede servir tanto para hacer frente a situaciones de extrema gravedad causadas por la naturaleza, (un mal uso de) la ciencia o la tecnología, o un accidente fortuito, como para afrontar aquellas otras que, sin tener necesariamente ese origen natural, tecnológico, científico o accidental, pueden dar lugar a una paralización de servicios esenciales para la comunidad y/o un desabastecimiento de productos de primera necesidad. $Y$ es que nada impediría entender que ambas situaciones podrían venir motivadas por, o podrían dar lugar a, una crisis política o un conflicto social graves. En tal caso, lo determinante para defender la aplicación de uno u otro estado (alarma o excepción) sería no tanto el hecho en sí, como la necesidad de tener que proceder solo a la limitación o también a 
la suspensión de ciertos derechos fundamentales (los previstos en el art. 55.1 $\mathrm{CE})$.

A esta misma conclusión nos conduce, según hemos visto ya, un análisis de las medidas que prevé el art. 11 LOAES para hacer frente a la emergencia ${ }^{51}$; y es que, en efecto, no parece que las mismas "piensen" con igual intensidad en los distintos supuestos que pueden dar lugar a la declaración del estado de alarma. Por el contrario, da la impresión de que la preocupación principal del legislador tiene que ver con la necesidad de ofrecer una respuesta a aquellas situaciones que puedan suponer un desabastecimiento de productos de primera necesidad así como una paralización de servicios esenciales para la comunidad, lo que se ve reforzado con la previsión del art. 12.2 de la propia LOAES, al disponer que "el Gobierno podrá acordar la intervención de empresas o servicios, así como la movilización de su personal, con el fin de asegurar su funcionamiento", siendo de "aplicación al personal movilizado la normativa vigente sobre movilización que, en todo caso, será supletoria respecto de lo dispuesto en el presente artículo".

Curiosamente, no hay ninguna medida que de manera específica se dedique a hacer frente a las crisis naturales, accidentales o sanitarias a que se refieren los apartados a) y b) del art. 4 LOAES, más allá de la remisión que hace el art. 12.1 de esta misma ley a las medidas "establecidas en las normas para la lucha contra las enfermedades infecciosas, la protección del medio ambiente, en materia de aguas y sobre incendios forestales"52. Se ha de insistir, a este respecto, en la idea de que si es posible dar una respuesta adecuada a esas situaciones acudiendo al derecho ordinario (la legislación sectorial correspondiente en materia de protección civil, incendios forestales, salud

\footnotetext{
${ }^{51}$ Artículo 11 LOAES: "Con independencia de lo dispuesto en el artículo anterior, el decreto de declaración del estado de alarma, o los sucesivos que durante su vigencia se dicten, podrán acordar las medidas siguientes:

a) Limitar la circulación o permanencia de personas o vehículos en horas y lugares determinados, o condicionarlas al cumplimiento de ciertos requisitos.

b) Practicar requisas temporales de todo tipo de bienes e imponer prestaciones personales obligatorias.

c) Intervenir y ocupar transitoriamente industrias, fábricas, talleres, explotaciones o locales de cualquier naturaleza, con excepción de domicilios privados, dando cuenta de ello a los Ministerios interesados.

d) Limitar o racionar el uso de servicios o el consumo de artículos de primera necesidad.

e) Impartir las órdenes necesarias para asegurar el abastecimiento de los mercados y el funcionamiento de los servicios de los centros de producción afectados por el apartado d) del artículo cuarto".

${ }^{52}$ SOLOZÁBAL ECHAVARRÍA, J. J., "Algunas consideraciones constitucionales..., p. 9.
} 
pública, medio ambiente, etc.), no estará nunca justificada la declaración del estado de alarma ${ }^{53}$.

En último término, corresponde al Gobierno valorar si se da alguna de estas situaciones. A tal efecto, dispone de un amplio margen de discrecionalidad política y jurídica ${ }^{54}$, sin perjuicio de que dicha decisión, plasmada normativamente en el Decreto de declaración del estado de alarma, pueda ser controlada políticamente por el Congreso, y jurisdiccionalmente, de acuerdo con criterios técnicos, por el Tribunal Constitucional ${ }^{55}$, como corresponde a una norma con valor de ley, tal y como el propio Tribunal se encargó de dejar claro en su Auto de 13 de enero de 2012 (ATC 7/2012).

\section{BREVE REFERENCIA A LAS CUATRO EXPERIENCIAS PRÁCTICAS DE DECLARACIÓN DEL ESTADO DE ALARMA}

El primer estado de alarma declarado en España estuvo vigente durante cuarenta y tres días, desde el 4 de diciembre de 2010 (fecha de su declaración mediante Real Decreto 1673/2010) hasta el 15 de enero de 2011 (fecha de finalización de la prórroga acordada en el Real Decreto 1717/2010, de 17 de diciembre).

Lo motivó una huelga encubierta (abusiva e ilegal) de un alto número de controladores civiles de tránsito aéreo, disconformes con la regulación de su convenio profesional. Los precedentes hay que buscarlos en el Decreto-ley de 5 de febrero de 2010, mediante el que se devolvía a AENA la gestión y el control que de manera autónoma llevaban practicando los controladores desde 1999 (autorregulación), y en la ley 9/2010, de 14 de abril, que estableció nuevas condiciones laborales para los mismos, incluida una rebaja de su salario. Ambas disposiciones fueron recurridas por los controladores sin éxito alguno. Además, se ha de tener en cuenta que el 5 de agosto de 2010, mediante Real Decreto 1001/2010, el Gobierno estableció unas nuevas normas de seguridad aeronáutica que afectaban a la duración de su jornada laboral (incluidos los tiempos de descanso), que tampoco resultó de su agrado. Todo

\footnotetext{
${ }^{53}$ Como señala Vicente Álvarez, "los supuestos fácticos descritos deben venir cualificados por una gravedad tal, que haga que razonablemente sólo puedan ser superadas las situaciones de peligro mediante el recurso a este estado excepcional". Vid. ÁLVAREZ GARCÍA, V., "EI coronavirus..., p. 11.

${ }_{54}$ ÁLVAREZ GARCÍA, V., "El coronavirus..., p. 11.

${ }^{55}$ SOLOZÁBAL ECHAVARRÍA, J. J., "Algunas consideraciones constitucionales..., p. 8.
} 
ello provocó un malestar creciente que acabó desembocando en ausencias reiteradas de los mismos a sus puestos de trabajo, por entender que habían sobrepasado el límite de sus horas laborales, sin que el Gobierno reconociese la certeza de tales argumentos, al ratificar mediante Real Decreto-ley 13/2010, de 3 de diciembre, la jornada laboral aprobada el 5 de agosto. Así las cosas, la respuesta inmediata de numerosos controladores aéreos fue abandonar de manera concertada su puesto de trabajo alegando que no se encontraban en condiciones físicas y psíquicas adecuadas para poder desempeñarlo adecuadamente, tal y como disponía la Ley $21 / 2003$, de 7 de julio, de Seguridad Aérea. Ante tal situación, que coincidía además con un momento de gran intensidad del tráfico aéreo, pues eran vísperas del largo puente de la Constitución, con las fiestas navideñas a la vista, el Gobierno acordó, primero, militarizar el servicio de gestión del tráfico aéreo, y declarar, después, ante la ineficacia de la primera medida, el primer estado de alarma de nuestra democracia, mediante el Real Decreto 1673/2010, de 4 de diciembre ${ }^{56}$.

De conformidad con su Exposición de Motivos, las razones que llevaron al Gobierno a tomar tan drástica decisión no fueron otras que "[l]as circunstancias extraordinarias que concurren por el cierre del espacio aéreo español como consecuencia de la situación desencadenada por el abandono de sus obligaciones por parte de los controladores civiles de tránsito aéreo, [que] impiden el ejercicio del derecho fundamental (...) [a la libertad de circulación] y determinan la paralización de un servicio público esencial para la sociedad como lo es el servicio de transporte aéreo. Todo ello constituye, sin duda, una calamidad pública de enorme magnitud por el muy elevado número de ciudadanos afectados, la entidad de los derechos conculcados y la gravedad de los perjuicios causados". En concreto, en el art. 1 Real Decreto 1673/2010 se hacía referencia expresa al apartado c) en relación con los apartados a) y d) del art. 4 LOAES, de lo que cabe deducir que, según el Gobierno, se había producido una paralización de servicios públicos esenciales para la comunidad (como consecuencia de la realización de una huelga abusiva que no respetaba los servicios mínimos) -apartado c)-, provocando así una calamidad pública -apartado a)- y una situación de desabastecimiento de productos de primera necesidad -apartado d)-.

\footnotetext{
${ }^{56}$ Vid. un resumen de los hechos en ABA CATOIRA, A., "El estado de alarma..., pp. 305 ss.
} 
Dejando ahora de lado esta última situación, pues no parece que se produjera de facto ningún desabastecimiento ${ }^{57}$, cabría preguntarse si se dan, efectivamente, una paralización de algún servicio público esencial para la comunidad y una calamidad pública, tal y como el Gobierno sostiene con insistencia a lo largo del Real Decreto. Sin negar lo primero, pues resulta evidente que la paralización del tráfico aéreo puede ser calificada como tal ${ }^{58}$, puede ser más dudoso lo segundo a partir de una interpretación sistemática de los distintos términos empleados en el apartado a) del art. 4 LOAES, pues parece que, en efecto, las calamidades públicas aquí referidas se encuentran vinculadas a hechos naturales o accidentes de gran magnitud, sin que quepa encuadrar entre los mismos los supuestos de huelgas ilegales o abusivas consecuencia de un conflicto laboral latente ${ }^{59}$. Antes bien, parecería que este supuesto, dejando de lado ahora otro tipo de consideraciones, encajaría mejor con el previsto en el art. 13.1 LOAES $^{60}$.

Desde esta perspectiva, resulta, por consiguiente, problemático entender que el cierre del espacio aéreo es encuadrable en alguno de los cuatro supuestos a que se refiere el art. 4 LOAES para poder declarar legítimamente el estado de alarma $^{61}$. No se pone en duda la gravedad de la situación (con seria afectación de derechos de terceros -libre circulación- derivada del no mantenimiento de servicios esenciales para la comunidad) generada por ese hecho (ausencia injustificada del puesto de trabajo que no se puede calificar de ejercicio del

\footnotetext{
${ }^{57}$ Así lo señalan, entre otros, REQUEJO RODRíGUEZ, P., "Teoría vs. práctica del estado de alarma..., p. 1502; o ESPÍN LÓPEZ, I., "Estado de alarma en el sistema constitucional español: espacio aéreo", Revista Acta Judicial, 2, 2018, p. 125.

${ }^{58}$ ESPÍN LÓPEZ, I., "Estado de alarma..., pp. 122.-123.

${ }^{59}$ De otra opinión, ESPÍN LÓPEZ, I., "Estado de alarma..., p. 124, para quien la lista del apartado a) del art. 4 LOAES no es cerrada, en tanto que este precepto emplea los términos 'tales como'.

${ }^{60}$ Lo han apuntado, entre otros, REQUEJO RODRÍGUEZ, P., "Teoría vs. práctica del estado de alarma..., p. 1502-1503; y VIDAL PARDO, C., DELGADO RAMOS, D., "Algunas consideraciones sobre la declaración del estado de alarma y su prórroga", Revista Española de Derecho Constitucional, 92, 2011, pp. 253 ss., si bien, más por razones de oportunidad que de otro tipo, no han llegado al punto de defender que hubiera sido preferible declarar en este caso el estado de excepción.

${ }^{61}$ Lo niega expresamente SIEIRA MUCIENTES, S., "Estado de alarma"..., p. 287, para quien lo que procedía era haber declarado el estado de excepción. No obstante, sin entrar a valorar ahora si en la declaración del estado de alarma y, sobre todo, su prórroga, así como en lo relativo al discutible sometimiento de los controladores aéreos (civiles) a la jurisdicción militar se cumplieron los requisitos constitucionales y legales, sí interesa destacar que, en relación con este último aspecto, resulta, en efecto, especialmente cuestionable que personal civil pueda quedar sujeto a la jurisdicción militar fuera del estado de sitio, con la afectación severa que además ello conlleva para el ejercicio de ciertos derechos fundamentales. Vid. VIDAL PARDO, C., DELGADO RAMOS, D., "Algunas consideraciones..., pp. 255 ss.; y REQUEJO RODRÍGUEZ, P., "Teoría vs. práctica del estado de alarma..., pp. 1506 ss.
} 
derecho de huelga), sino la adecuación del mismo a las previsiones de la ley, hasta el punto de que sería posible preguntarse, como se hizo hace un instante, si la situación no se debería haber afrontado mejor o bien mediante la legislación sectorial correspondiente o bien mediante la declaración del estado de excepción ${ }^{62}$, dejando de lado ahora otro tipo de razones sobre la conveniencia u oportunidad de declarar este, y acerca de su más complejo procedimiento de declaración, que podría resultar inapropiado por motivos de urgencia $^{63}$. Sea como fuere, lo cierto es que el Tribunal Constitucional, en la ya mencionada Sentencia 83/2016, de 28 de abril, confirmó la constitucionalidad de esta declaración del estado de alarma.

A través de esta experiencia práctica, se pone claramente de manifiesto que el presupuesto de hecho habilitante del estado de alarma no tiene por qué estar única y exclusivamente vinculado a causas naturales o accidentales, aunque ese sea su principal campo de acción. Por el contrario, cabría entender, como venimos haciendo aquí, que este instrumento constitucional también puede ser útil para dar una respuesta jurídicamente ponderada a situaciones graves que pueden derivar de (o desembocar en) un conflicto político o social. En este concreto caso de los controladores aéreos, la base jurídica que permitió la declaración del estado de alarma podemos encontrarla, como hizo el Gobierno, en el apartado c) -paralización de un servicio esencial para la comunidad- en conexión con el apartado d) -desabastecimiento de productos de primera necesidad- del art. 4 LOAES. Ciertamente, se trata de una conexión un tanto difícil, pues, como hemos señalado, tal desabastecimiento, en el momento de declarar el estado de alarma, no se había llegado a producir, pero nada impide entender que esta situación podría haber llegado a darse si la práctica paralización del tráfico aéreo se hubiera prolongado en el tiempo. Entra dentro de la lógica de este supuesto del apartado d) del art. 4 LOAES que el Gobierno pueda reaccionar mediante esta medida tan extraordinaria (estado de alarma) para evitar que se llegue a consumar lo que parece inevitable sin dicha reacción preventiva. $\mathrm{Y}$ que no tenga que acudir a la declaración del estado de

\footnotetext{
62 ABA CATOIRA, A., "El estado de alarma..., p. 335.

${ }^{63}$ Como bien resume Carlos Garrido, para algunos autores, "la urgencia, la necesidad y la proporcionalidad de la respuesta convirtieron la declaración del estado de alarma en la fórmula más adecuada para enfrentar la emergencia, aunque formalmente no procediera"; sin embargo, no es esa su posición, pues él sostiene que a partir de un entendimiento adecuado de la naturaleza bifronte del estado de alarma es perfectamente posible entender que este puede ser declarado también cuando el hecho que lo provoque derive de un grave conflicto político-social, tal y como sucedió en el caso de la huelga ilegal de los controladores aéreos (GARRIDO LÓPEZ, C., "La naturaleza bifronte..., pp. 386 ss.).
} 
excepción, indudablemente más grave, si no es preciso proceder a la suspensión de alguno de los derechos fundamentales previstos en el art. 55.1 CE, como fue el caso.

La segunda vez que el Gobierno declaró el estado de alarma fue el 14 de marzo de 2020 (Real Decreto 463/2020, modificado por el Real Decreto 465/2020, de 17 de marzo), con el fin de tratar de poner freno a la extensión de una pandemia global de origen vírico (coronavirus COVID-19), que estaba (está) causando numerosas muertes y poniendo en riesgo el sostenimiento del sistema sanitario. La gravedad de la situación hizo que tuviera que ser prorrogado hasta en seis ocasiones, tras obtener las preceptivas autorizaciones parlamentarias (cada vez con un respaldo menor), poniéndose fin al mismo el 21 de junio de 2020.

Según el art. 1 del Real Decreto 463/2020, este estado de alarma se declara al amparo de lo dispuesto en los apartados b) y d) LOAES ${ }^{64}$. Pocas dudas ofrece la remisión al apartado b), dado que, en efecto, nos encontramos ante una "epidemia" (caracterizada de pandemia global por la Organización Mundial de la Salud el 11 de marzo) que está provocando una grave "crisis sanitaria"65. Quizás ofrezca alguna duda más la remisión al apartado d), en la medida en que cuando se declaró el estado de alarma no nos encontrábamos, de facto, ante una situación de desabastecimiento de productos de primera necesidad; no obstante, el carácter previsor de la medida también aquí resulta perfectamente justificado.

Las medidas adoptadas en aplicación del estado de alarma "para proteger la salud y seguridad de los ciudadanos, contener la progresión de la enfermedad y reforzar el sistema de salud pública" (según la Exposición de Motivos del citado Real Decreto 463/2020) fueron muy severas ${ }^{66}$, con grave afectación a ciertos derechos fundamentales (sobre todo, la libertad de circulación ${ }^{67}$ ), hasta

\footnotetext{
${ }_{65}^{64}$ Aunque en el Preámbulo solo se hace referencia al apartado b).

${ }^{65}$ Como subraya Vicente Álvarez, "para la lucha contra las crisis sanitarias el estado excepcional apropiado es el de alarma (...), porque así lo establece la LOAES (que es la que realmente regula su contenido). (...) Sólo si estas emergencias (ahora sanitarias) derivasen en el futuro en gravísimas perturbaciones del orden público podría recurrirse a la declaración del estado de excepción o, en caso realmente extremo, del estado de sitio". Vid. ÁLVAREZ GARCÍA, V., "El coronavirus..., p. 10.

${ }^{66}$ Un resumen de las mismas en SIEIRA MUCIENTES, S., "Estado de alarma"..., pp. 284 ss., y ÁLVAREZ GARCÍA, V., "El coronavirus..., pp. 17 ss. Hay que tener en cuenta, además, que las medidas incluidas en el decreto de declaración del estado de alarma y en los de las sucesivas prórrogas se vieron complementadas por las aprobadas mediante numerosos decretos-leyes.

${ }_{67}$ Aunque también se vieron seriamente afectados otros derechos y libertades, tales como el derecho reunión y manifestación, el derecho de sufragio, la libertad de culto y la libertad de
} 
el punto de que hubo un vivo debate (académico, fundamentalmente) sobre si se había llegado a sobrepasar el límite de la restricción para dar paso, directamente, a una auténtica suspensión, sobre todo, del referido derecho a la libertad de circulación, lo que le estaría vedado al estado de alarma (no así al de excepción) ${ }^{68}$.

No es el propósito de este trabajo analizar en dónde se encuentra la difusa frontera que nos permite distinguir "limitación" de "suspensión" de los derechos fundamentales ${ }^{69}$, si bien ya dejamos constancia en su momento de que, pese a la severidad de la restricción, no nos parecía que la misma pudiese ser calificada de suspensión ${ }^{70}$. Habrá que estar atentos, en todo caso, a la

empresa. Vid. FERNÁNDEZ DE GATTA SÁNCHEZ, D., "El estado de alarma en España por la epidemia del coronavirus y sus problemas", Revista General de Derecho Constitucional, 33, 2020, pp., p. 20.

68 Fueron, en efecto, abundantes los artículos de prensa tomando posición sobre esta controversia. A título de mero ejemplo, véase, a favor de la declaración del estado de alarma, básicamente por entender que no ha tenido lugar una crisis de orden público originada por un conflicto político, y no se han llegado a suspender derechos fundamentales, TAJADURA TEJADA, J., "Derecho de crisis y Constitución", El País, 20.03.2020 (https://elpais.com/elpais/2020/03/16/opinion/1584364474_350250.html); MARTíNEZ ALARCÓN, Mํ. L., "¿Es el estado de alarma en España un estado de excepción encubierto?", The Conversation, 02.04.2020 (https://theconversation.com/es-el-estado-de-alarma-en-espanaun-estado-de-excepcion-encubierto-135358); CRUZ VILLALÓN, P., "La Constitución bajo el estado de alarma", El País, 17.04.2020

https://elpais.com/elpais/2020/04/16/opinion/1587025782_733659.html); en contra, por entender que correspondía declarar el estado de excepción, dado que se había producido una suspensión de derechos, DÍAZ REVORIO, F. J., "A vueltas con la suspensión de los derechos fundamentales", Almacén de Derecho, 09.04.2020 (https://almacendederecho.org/a-vueltascon-la-suspension-de-los-derechos-fundamentales); Aragón Reyes, M.: "Hay que tomarse en serio la Constitución", El País, 10.04.2020

(https://elpais.com/elpais/2020/04/09/opinion/1586420090_736317.html).

69 Solozábal entiende que la limitación es una "restricción lícita" del derecho fundamental, "llevada a cabo por exigencias de su afirmación universal o para asegurar su compatibilidad con otros bienes y derechos", mientras que la suspensión consiste en la "privación temporal o episódica de un derecho", sin que en ningún caso ello suponga su pérdida (SOLOZÁBAL ECHAVARRÍA, J. J., "Algunas consideraciones constitucionales..., p. 10).

Esta dificultad de diferenciación entre "limitación" y "suspensión" también ha sido abordada por el Tribunal Constitucional en distintas ocasiones; así, como recuerda SIEIRA MUCIENTES, S., "Estado de alarma"..., pp. 294-295, en la STC 292/2000, de 30 de noviembre (FJ 11), el TC distingue entre "restricciones directas del derecho fundamental mismo" y "restricciones al modo, tiempo, o lugar de ejercicio del derecho fundamental", lo que ha sido aprovechado por parte importante de la doctrina (ÁLVAREZ GARCÍA, BACIGALUPO, DE LA QUADRASALCEDO, TAJADURA o VELASCO entre ellos) para defender la adecuación del estado de alarma a la crisis sanitaria de 2020 , al entender que "las medidas tomadas, en particular la obligación de confinamiento de la práctica totalidad de la ciudadanía, se trataría de restricciones de modo, tiempo y lugar, que además vendrían justificadas en su conformidad con los principios de necesidad y proporcionalidad". En este mismo sentido, GARRIDO LÓPEZ, C., "La naturaleza bifronte..., pp. 390 ss., entiende que ninguna de las restricciones de derechos, pese a su intensidad, implicaron suspensión.

${ }^{70}$ ARROYO GIL, A., "¿Estado de alarma o estado de excepción?", Agenda Pública, 12.04.2020 (http://agendapublica.elpais.com/estado-de-alarma-o-estado-de-excepcion/). De otra opinión, además de los autores referidos anteriormente, SIEIRA MUCIENTES, S., "Estado de alarma"..., 
resolución por parte del Tribunal Constitucional del recurso de inconstitucionalidad (núm. 2054-2020) promovido por más de cincuenta diputados del Grupo Parlamentario de Vox, y admitido a trámite por providencia de 6 de mayo de 2020.

Sea como fuere, lo cierto es que las medidas adoptadas por el Gobierno de España a lo largo de esos meses tenían como fin único proteger la salud y seguridad de los ciudadanos, así como contener la progresión de la enfermedad y reforzar el sistema de salud pública. Medidas, por cierto, que se venían a sumar a las ya acordadas con carácter previo por las Comunidades autónomas, e, incluso, los Ayuntamientos, y a las que seguirían aprobando posteriormente ${ }^{71}$, con base en el derecho sanitario y, fundamentalmente, en la Ley Orgánica 3/1986, de 14 de abril, de medidas especiales en materia de salud pública ${ }^{72}$, así como, por lo que se refiere a los Ayuntamientos, en la Ley

pp. 295 ss., quien se muestra claramente convencida de que durante la vigencia del estado de alarma de 2020 se produjo una auténtica suspensión de derechos y "se cumplía el supuesto de hecho del estado de excepción, sin forzar en modo alguno la dicción literal del artículo 13.1 de la LOEAES"; a su juicio, "[a] todas luces, la crisis desbordaba el marco de una simple crisis sanitaria y tenía connotaciones de quiebra grave del orden público en los términos señalados por la Ley Orgánica -pues tocaba de lleno a la participación ciudadana-". En la misma línea, FERNÁNDEZ DE GATTA SÁNCHEZ, D., "El estado de alarma..., pp. 23 ss., apunta, además, que también lo han entendido así las Salas de lo Contencioso-administrativo de los Tribunales Superiores de Justicia de Navarra y Aragón, en sus Sentencias 69/2020, de 30 de abril, y $151 / 2020$, de 30 de abril, respectivamente, en las que revocaron sendas prohibiciones de concentración y manifestación convocadas para el 1 de mayo, decretadas por la Delegación del Gobierno correspondiente, por entender que los derechos fundamentales solo se pueden suspender en el estado de excepción. Véase asimismo el interesante resumen que realiza este autor de distintos Autos del Tribunal Supremo que resuelven medidas cautelares solicitadas o recursos interpuestos en procedimientos iniciados contra la declaración del estado de alarma (pp. 31-37).

${ }_{71}$ Vid. SIEIRA MUCIENTES, S., "Estado de alarma..., pp. 289-290.

${ }^{72}$ Aunque también se adoptaron medidas en base a otras normas que ofrecen igualmente cobertura legal para la intervención en situaciones de crisis: Ley 14/1986, de 25 de abril, General de Sanidad; Ley 33/2011, de 4 de octubre, General de Salud Pública; Ley 17/2015, de 9 de julio, del Sistema Nacional de Protección Civil; e, incluso, la Ley 36/2015, de 28 de septiembre, de Seguridad Nacional. Vid. ÁLVAREZ GARCÍA, V., "El coronavirus..., p. 9; SIEIRA MUCIENTES, S., "Estado de alarma..., pp. 290-291; y FERNÁNDEZ DE GATTA SÁNCHEZ, D., "El estado de alarma..., pp. 18-19.

Esta normativa sectorial ofrece, en efecto, una amplia cobertura para la adopción de numerosas medidas extraordinarias por parte de la autoridad competente (estatal 0 autonómica), hasta el punto de que se ha llegado a considerar innecesaria la declaración del estado de alarma. Vid. MATEU-ROS CEREZO, R., "Estados de alarma, excepción y sitio", en AA. VV., Gobierno y Administración en la Constitución, vol. I, IEF, Madrid, 1988, p. 202; y BAÑO LEÓN, J. M., "Confusión regulatoria en la crisis sanitaria", Almacén de Derecho, 29.10.2020, pp. 2 ss.

A este respecto, Quadra-Salcedo Janini entiende que "[n]o son (...) el tipo de restricciones de derechos que se pueden adoptar en una situación de crisis sanitaria lo que singulariza al estado de alarma, sino la alteración del órgano competente para adoptarlas", respondiendo a la pregunta: "¿para qué se ha previsto entonces en la propia Constitución el estado de alarma, si se puede prescindir de él para hacer lo mismo?" del modo siguiente: "precisamente para poder 
7/1985, de 2 de abril, Reguladora de las Bases del Régimen Local, en cuyo art. 21.1.m) se atribuye al Alcalde, como Presidente de la Corporación, la atribución de "[a]doptar personalmente, y bajo su responsabilidad, en caso de catástrofe 0 de infortunios públicos o grave riesgo de los mismos, las medidas necesarias y adecuadas dando cuenta inmediata al Pleno" ${ }^{73}$. Muchas de estas medidas, por cierto, sin estar amparadas por el derecho de excepción, suponían ya una afectación importante de ciertos derechos fundamentales ${ }^{74}$.

La controversia sobre la constitucionalidad o legalidad de la declaración de este estado de alarma, y sus sucesivas prórrogas, se ha centrado, por tanto, no en la concurrencia de uno de los supuestos previstos en el art. 4 LOAES -claramente, el del apartado b)- sino en el alcance de las medidas adoptadas por el Gobierno en su declaración, y autorizadas por el Congreso en las prórrogas subsiguientes, en cuanto que pueden haber significado una auténtica suspensión de derechos fundamentales. Ello pone de relieve la dificultad de ajuste entre el llamado presupuesto de hecho habilitante del estado de alarma y el alcance de las medidas que se podrían considerar necesarias para abordar la emergencia. En este caso, en efecto, el supuesto de hecho (pandemia global) responde perfectamente a la previsión del art. 4.b) LOAES, pero las medidas adoptadas para hacerle frente suscitan, cuando menos, ciertas dudas, derivadas de la no siempre fácil distinción entre limitación y suspensión de derechos fundamentales.

Concluido el segundo estado de alarma, tras más de tres meses de vigencia, el 21 de junio de 2020, durante todo el verano y el primer mes de otoño de este

atribuir el poder de hacerlo a aquel que de manera ordinaria no es el competente y sin tener que esperar a que el que lo es, adopte una decisión que no es imperativa ni reglada" (QUADRA-SALCEDO JANINI, T. DE LA, "Estado autonómico y lucha contra la pandemia", en BIGLINO CAMPOS, P., DURÁN ALBA, J. F. (dirs.), Los efectos horizontales de la COVID sobre el sistema constitucional, Col. Obras colectivas, Fundación Manuel Giménez Abad, Zaragoza, 2020, p. 23). En la misma línea, Alba Nogueira sostiene que "no parece que pueda afirmarse que entre una u otra forma de abordar la gestión de la crisis -Derecho sanitario vs. Estado de alarma- existan grandes diferencias en cuanto al alcance concreto de las medidas que permiten (...), salvo si lo pretendido era, precisamente, el desapoderamiento competencial de los gestores sanitarios autonómicos" (NOGUEIRA LÓPEZ, A., "Confinar el coronavirus. Entre el viejo derecho sectorial y el derecho de excepción", El Cronista del Estado Social y Democrático de Derecho, 86-87, 2020, p. 30). De la misma opinión, BOIX PALOP, A., "COVID-19: La batalla jurídica contra la pandemia y los estados de alarma 'territorializados'", The Conversation, 03.09.2020. Discrepa, sin embargo, BARNÉS, J., "Falsos dilemas en la lucha contra la pandemia", Almacén de Derecho, 27.08.2020, para quien "la privación, suspensión o grave limitación de los derechos fundamentales con un alcance general (...) no pueden ser adoptadas por las autoridades sanitarias en nuestro ordenamiento jurídico, y requieren con carácter previo la correspondiente declaración de emergencia del Gobierno".

${ }^{73}$ Vid. ÁLVAREZ GARCÍA, V., "El coronavirus..., p. 15.

${ }^{74}$ Vid. NOGUEIRA LÓPEZ, A., "Confinar el coronavirus..., pp. 23 ss. 
mismo año las Comunidades autónomas recuperaron la plenitud del ejercicio de sus competencias, asumiendo la gestión de la crisis sanitaria, que, aunque se vio aliviada, en absoluto desapareció. Fue un período complejo ${ }^{75}$ en el que algunas Comunidades autónomas adoptaron medidas, sobre cuya constitucionalidad otras manifestaban sus dudas (como, por ejemplo, en relación con el cierre perimetral de algunos municipios). Ello provocó la intervención de coordinación del Ministerio de Sanidad, Consejo Interterritorial mediante, muy discutida también por alguna Comunidad autónoma, muy en particular, la de Madrid $^{76}$, lo que condujo a la declaración de un nuevo estado de alarma, con un ámbito territorial limitado a determinados municipios de esta región, durante quince días, por medio del Real Decreto 900/2020, de 9 de octubre, y con idéntica base jurídica (art. 4.b) LOAES).

Hubo además resoluciones judiciales contradictorias acerca de la competencia de los órganos judiciales para ratificar medidas que supusiesen una limitación de algún derecho fundamental, lo que llevó a una modificación, igualmente cuestionada, de la Ley 29/1998, de 13 de julio, reguladora de la Jurisdicción Contencioso-Administrativa (a través de la Ley 3/2020, de 18 de septiembre). En concreto, se modificó, entre otras cosas, su art. 8.6, a fin de atribuir "a los Juzgados de lo Contencioso-Administrativo la autorización o ratificación judicial de las medidas adoptadas con arreglo a la legislación sanitaria que las autoridades sanitarias consideren urgentes y necesarias para la salud pública e impliquen limitación o restricción de derechos fundamentales cuando dichas medidas estén plasmadas en actos administrativos singulares que afecten

\footnotetext{
${ }^{75}$ Muy crítico con esta práctica sustitución del Estado por las Comunidades autónomas, que ha generado "la descoordinación, la confusión e, incluso, el enfrentamiento territorial en algunos casos, [lo] que no contribuye a la eficacia de las decisiones autonómicas que se han ido tomando", se muestra ARAGÓN REYES, M., "Epílogo", en BIGLINO CAMPOS, P., DURÁN ALBA, J. F. (dirs.), Los efectos horizontales de la COVID sobre el sistema constitucional, Col. Obras colectivas, Fundación Manuel Giménez Abad, Zaragoza, 2020, pp. 8 ss. Según Aragón, en el concreto caso de las medidas adoptadas en materia de sanidad y educación, "ni el Estado puede rehuir su responsabilidad en la adopción de medidas sanitarias y educativas para hacer frente a la pandemia, ni las comunidades autónomas (...) pueden sustituir la obligación de regulación (e incluso a veces de ejecución) básica que sólo al Estado corresponde". A mayor abundamiento, según este autor, "lo que en realidad ha sucedido es que la abstención del Estado en el cumplimiento diligente de sus competencias frente a la nueva ola de pandemia, endosándoselas a las comunidades autónomas, ha propiciado que estas hayan adoptado determinadas y muy intensas medidas limitativas de derechos fundamentales (...) para las que es muy dudoso que tengan competencias". Lo que le lleva a concluir que "[r]ealmente, y de modo insólito, estamos asistiendo a una especie de 'estados de alarma' no adoptados por el Gobierno estatal sino por las comunidades autónomas, con evidente desvío de lo constitucionalmente previsto".

${ }_{76}$ Vid. ARROYO GIL, A., "Alarma en Madrid", Agenda Pública, 27.09.2020 (https://agendapublica.es/alarma-en-madrid/).
} 
únicamente a uno o varios particulares concretos e identificados de manera individualizada"; y el art. 10.8, para atribuir a los Tribunales Superiores de Justicia idéntica facultad "cuando sus destinatarios no estén identificados individualmente". En ejercicio de tal facultad, algunos órganos judiciales desestimaron la ratificación de medidas, por considerar incompetente a la Comunidad autónoma para su adopción, que otros, respecto de medidas similares, sí ratificaron ${ }^{77}$.

Ante esta situación, en la que por encima de todo primaba la inseguridad jurídica, el Gobierno acordó declarar, de nuevo, con carácter general en todo el territorio nacional, el estado de alarma, a través del Real Decreto 926/2020, de 25 de octubre, al amparo, una vez más, de lo dispuesto en el apartado 4.b) LOAES, designando como autoridad delegada al Presidente/a de cada Comunidad o Ciudad autónoma (en aplicación, ciertamente un tanto discutible, de la previsión del art. 7 LOAES) ${ }^{78}$. Y, dado que la situación no mejoraba, el propio Gobierno, previa Resolución de 29 de octubre de 2020 del Congreso de los Diputados, por la que se ordena la publicación del Acuerdo de autorización de la prórroga del estado de alarma, acordó esta por Real Decreto 956/2020, de 3 de noviembre; prórroga que entró en vigor a las 00:00 horas del día 9 de noviembre de 2020, y que se extiende durante un plazo de seis meses, hasta las 00:00 horas del día 9 de mayo de 2021, lo que resulta a todas luces excesivo $^{79}$.

A fecha de cierre de estas páginas (31 de enero de 2021), esta es la situación jurídica en la que nos encontramos, sujetos a un estado de alarma ciertamente peculiar, en tanto en que a través de él lo que se persigue es ofrecer cobertura jurídica a las Comunidades autónomas a fin de que las mismas puedan adoptar distintas medidas para hacer frente a la crisis sanitaria; medidas que, en

\footnotetext{
${ }_{77}^{77}$ Vid. Baño León, J. M.: "Confusión regulatoria..., p. 1.

${ }^{78}$ Discutible porque, según dispone el art. 7 LOAES, "[a] los efectos del estado de alarma la Autoridad competente será el Gobierno o, por delegación de este, el Presidente de la Comunidad Autónoma cuando la declaración afecte exclusivamente a todo o parte del territorio de una Comunidad". Dado que, en este caso, la declaración afecta a todo el territorio del Estado (no solo al de alguna/s Comunidad/es autónoma/s), lo lógico hubiese sido entender que tal delegación no cabía. Además, lo que permite este art. 7 LOAES es delegar la gestión o ejecución de las medidas, cuando las mismas fuesen aplicables solo en su territorio, pero no propiamente la decisión de su adopción, dado que eso corresponde en exclusiva al Gobierno de España mediante el Real Decreto de declaración del estado de alarma, una norma que, como hemos visto, tiene valor de ley, según el Tribunal Constitucional (ATC 7/2012, de 13 de enero), lo que no sucede con las normas autonómicas que hacen efectivas en su territorio las susodichas medidas.

${ }_{79}$ Vid. ARROYO GIL, A., "¿Estado de alarma sin control?, Agenda Pública, 28.10.2020 (https://agendapublica.es/estado-de-alarma-sin-control/).
} 
realidad, correspondería aprobar al propio Gobierno. Al mismo tiempo, con este estado de alarma se pretender evitar que acaben dictándose resoluciones judiciales contradictorias en la ratificación o autorización preventiva de dichas medidas, tal y como había venido sucediendo con anterioridad. Ahora, en efecto, al estar reconocidas tales medidas con carácter uniforme en todo el territorio nacional en el Real Decreto que declara el estado de alarma, cada Comunidad autónoma las podrá hacer efectivas cuando lo considere conveniente sin temor a que recaiga una resolución judicial anulatoria ${ }^{80}$.

También en este caso habrá que estar atentos a que el Tribunal Constitucional resuelva el recurso de inconstitucionalidad interpuesto el 6 de noviembre de 2020 por más de cincuenta diputados del Grupo Parlamentario Vox contra los Reales Decretos de declaración y prórroga del estado de alarma y la Resolución del Congreso autorizando esta última.

A la espera de que el Tribunal se pronuncie, lo que ponen de relieve estas experiencias prácticas es que, sin perjuicio de que la definición constitucional y legal del estado de alarma sea deficiente, el mismo ha resultado útil para ofrecer una respuesta a emergencias derivadas tanto de hechos naturales (epidemia) como sociales (huelga ilegal y abusiva), que no demandan una suspensión de derechos ${ }^{81}$.

\section{CONCLUSIONES}

Frente al escepticismo inicial acerca de la virtualidad práctica de los estados excepcionales, en general, y del estado de alarma, más en particular, la práctica ha demostrado que, al menos, este último es "un instrumento constitucional versátil y sumamente funcional" para dar respuesta a situaciones extraordinarias de muy diversa naturaleza (restablecimiento del servicio de tráfico aéreo interrumpido como consecuencia de una huelga ilegal y abusiva o reducción del número de contagios provocados por una pandemia de origen vírico), sin entrar a valorar de nuevo ahora si el uso que se ha hecho del mismo se ajusta perfectamente a la legalidad en todos sus aspectos ${ }^{82}$.

\footnotetext{
${ }^{80}$ Muy crítico con esta solución, BAÑO LEÓN, J. M.: "Confusión regulatoria..., pp. 10 ss., para quien lo más lógico hubiese sido reformar la LO 3/1986 para aclarar las competencias de las Comunidades autónomas y modificar la LRJCA a fin de reducir el control preventivo a las medidas individuales que conlleven coerción física.

${ }^{81}$ GARRIDO LÓPEZ, C., "La naturaleza bifronte..., p. 381.

${ }^{82}$ GARRIDO LÓPEZ, C., "La naturaleza bifronte..., p. 372.
} 
Es cierto, sin embargo, que la normativa reguladora del estado de alarma adolece de cobertura (en cuanto a la enumeración de los supuestos en que puede ser declarado) y precisión suficientes, sin que para ello sirva la excusa de que no se puede ir mucho más lejos, dada la imprevisibilidad de las situaciones de emergencia que se pueden acabar dando en la realidad. Sin negar lo que de verdad hay en esta afirmación, sí parece posible, sin embargo, avanzar en la línea demandada, con claridad y buenas razones, por Carlos Garrido, que aboga por una reforma de la LOAES en la que se "debería recuperar la relación meramente enunciativa de los supuestos habilitantes del estado de alarma, asumir su naturaleza bifronte y clarificar su operatividad en situaciones de conflictividad social" ${ }^{83}$, en el bien entendido de que tal modificación legal sería perfectamente acorde al texto constitucional, que, como hemos visto, en absoluto exige una radical distinta naturaleza del estado de alarma y el de excepción.

Cuando la vida o la seguridad de las personas están en riesgo como consecuencia de hechos naturales, accidentes $u$ otras situaciones extraordinarias sobrevenidas, no cabe poner en duda la razón que asiste al Estado para dar una respuesta igualmente excepcional, en el caso de que la emergencia no sea abordable dentro de la normalidad. En estos casos, antes de acudir simplemente a los principios (necesidad, proporcionalidad, responsabilidad) que podrían justificar dicha actuación pública, dada su laxitud, se ha de tratar de agotar todas las posibilidades hermenéuticas que el ordenamiento ofrece mediante las reglas que establece, ya sean de orden constitucional o legal, en todo caso, mucho más concretas y, por tanto, controlables, política y jurisdiccionalmente.

Dicho de otro modo: aun asumiendo que la realidad, en sus manifestaciones más extraordinarias, no se deja fácilmente aprehender, de modo que siempre es posible encontrarnos ante circunstancias no previstas que podrían demandar una actuación enérgica de los poderes públicos, se ha de intentar, sin embargo, que la actuación de estos se desenvuelva dentro de los márgenes que el propio legislador (del rango que sea) haya dispuesto, justificando debidamente, en todo caso, sus decisiones.

En el concreto caso del estado de alarma, y aun asumiendo, como hemos hecho, que el mismo está previsto fundamentalmente para reaccionar frente a

${ }^{83}$ GARRIDO LÓPEZ, C., "La naturaleza bifronte..., p. 401. 
emergencias de origen natural o tecnológico, o frente a graves accidentes, se ha de admitir también que existen casos en los que los supuestos previstos para su declaración -particularmente, los de los apartado c) y d) del art. 4 LOAES- pueden ser consecuencia de conflictos de naturaleza social o política, que por no llegar a generar graves alteraciones del orden público que demanden la suspensión de ciertos derechos fundamentales, no exigirían directamente la declaración del estado de excepción. Lo mismo podría suceder en sentido contrario en relación con los supuestos de los apartados a) y b), es decir, que una catástrofe, calamidad o desgracia pública, causada por un hecho natural o un accidente, o una grave crisis sanitaria, pudieran acabar desembocando en una crisis política y/o social de grandes dimensión, con seria alteración del orden público, sin que su correcto tratamiento por parte del poder público demandase igualmente proceder a la declaración del estado de excepción, porque no fuera necesario proceder a la suspensión de derechos fundamentales.

En conclusión, y aun sin ánimo alguno de defender aquí la llamada "teoría gradualista" de los estados excepcionales, tampoco podemos ignorar la lógica de este tipo que se encuentra presente en nuestro derecho de excepción ${ }^{84}$, de ahí que resulte razonable sostener que cuando nos encontremos ante circunstancias extraordinarias que puedan encajar tanto en los supuestos del estado de alarma como en los del estado de excepción, se haya de optar siempre por el primero, salvo que la situación requiera irremediablemente la suspensión de alguno de los derechos fundamentales a que se refiere el art. 55.1 CE, en cuyo caso se habrá de acudir inexcusablemente a la declaración del segundo. Parece, en efecto, que eso es lo que demanda un ponderado entendimiento de nuestra insuficiente regulación constitucional y legal de los estados excepcionales.

\footnotetext{
${ }^{84}$ SERRANO ALBERCA, J. M., "Comentario al artículo 116", en GARRIDO FALLA, F. (coord.), Comentarios a la Constitución, Civitas, Madrid, 3ª ed., 2001, p. 1776; GARRIDO LÓPEZ, C., "La naturaleza bifronte..., p. 378.
} 